\title{
(2) Gut microbiome and health: mechanistic insights
}

\section{OPEN ACCESS}

${ }^{1}$ Human Microbiome Research Program, Faculty of Medicine, University of Helsinki, Helsinki, Finland

2Laboratory of Microbiology, Wageningen University,

Wageningen, The Netherlands ${ }^{3}$ Department of Internal Medicine I, Gastroenterology, Hepatology, Endocrinology \& Metabolism, Medical University Innsbruck, Innsbruck, Austria ${ }^{4}$ Louvain Drug Research Institute (LDRI), Metabolism and Nutrition research group (MNUT), UCLouvain, Université catholique de Louvain, Walloon Excellence in Life Sciences and BIOtechnology (WELBIO), Brussels, Belgium

\section{Correspondence to} Professor Patrice D Cani, Louvain Drug Research Institute, WELBIO, Metabolism and Nutrition, UCLouvain, Université catholique de Louvain, Brussels, Belgium;

patrice.cani@uclouvain.be

WMdV, HT, MVH and PDC contributed equally.

Received 15 December 202 Accepted 14 January 2022

Check for updates

(C) Author(s) (or their employer(s)) 2022. Re-use permitted under CC BY. Published by BMJ.

To cite: de Vos WM, Tilg $\mathrm{H}$ Van Hul M, et al. Gut Epub ahead of print: [please include Day Month Year]. doi:10.1136/

gutjnl-2021-326789

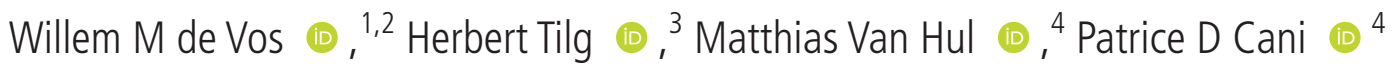

\section{ABSTRACT}

The gut microbiota is now considered as one of the key elements contributing to the regulation of host health. Virtually all our body sites are colonised by microbes suggesting different types of crosstalk with our organs. Because of the development of molecular tools and techniques (ie, metagenomic, metabolomic, lipidomic, metatranscriptomic), the complex interactions occurring between the host and the different microorganisms are progressively being deciphered. Nowadays, gut microbiota deviations are linked with many diseases including obesity, type 2 diabetes, hepatic steatosis, intestinal bowel diseases (IBDs) and several types of cancer. Thus, suggesting that various pathways involved in immunity, energy, lipid and glucose metabolism are affected.

In this review, specific attention is given to provide a critical evaluation of the current understanding in this field. Numerous molecular mechanisms explaining how gut bacteria might be causally linked with the protection or the onset of diseases are discussed. We examine well-established metabolites (ie, shortchain fatty acids, bile acids, trimethylamine $\mathrm{N}$-oxide) and extend this to more recently identified molecular actors (ie, endocannabinoids, bioactive lipids, phenolicderived compounds, advanced glycation end products and enterosynes) and their specific receptors such as peroxisome proliferator-activated receptor alpha (PPAR $\alpha)$ and gamma (PPAR $\gamma$ ), aryl hydrocarbon receptor (AhR), and G protein-coupled receptors (ie, GPR41, GPR43, GPR119, Takeda G protein-coupled receptor 5). Altogether, understanding the complexity and the molecular aspects linking gut microbes to health will help to set the basis for novel therapies that are already being developed.

\section{THE HUMAN GUT MICROBIOME}

The human microbiome is considered here as the collection of microbes, their genes and their products that colonise our body since birth and are transferred vertically. ${ }^{1}{ }^{2}$ While all body sites are colonised (figure 1), the highest microbial numbers are found in the gut that has been studied extensively. ${ }^{3}$ Here, we review the main and most recent findings that address the way gut microbes, their activities and mediator molecules can contribute to our health.

In healthy subjects, the oral and saliva microbiomes contain millions of microbes that are swallowed daily with our food, but their persistence in the gut is impeded by many factors, including the acidity of the stomach, the production of bile acids (BAs), digestive enzymes and antimicrobial proteins in the duodenum and beyond. A great number of other major variables affect further downstream microbial colonisation, such as chemical parameters like $\mathrm{pH}$, oxygen concentrations and redox potential, the biological production of mucus, bile and antibodies, as well as physical aspects, including gut architecture, peristalsis and transit times (figure 1). Hence, a concentration gradient of microbes is found along the small intestine, as microbial abundance in duodenal aspirates were found to be a 1000-fold lower than that of oral samples, although consisting of somewhat similar microbial taxa. ${ }^{4}$ Consequently, the small intestine contains an increasing number of thousands to several hundred million of cells per gram of content with partly oxygen-tolerant Firmicutes and Proteobacteria as major phyla. ${ }^{56}$ This all culminates in the lower gut where climax communities of up to 100 billion cells per gram reside for up to a few days, since transit in the colon is over a dozen times longer than that in the small intestine. Hence, the colonic microbiome is dominated by mainly anaerobic bacteria, including thousands of species and millions of genes, distributed among the major phyla of Firmicutes (predominantly Ruminococcaceae and Lachnospiraceae), Bacteroidetes, Actinobacteria, Proteobacteria and Verrucomicrobia (Akkermansia) ${ }^{7-10}$ (figure 1). Excreted as faeces, it is this biomass that makes up what is usually termed the gut microbiome that has been associated with a plethora of diseases and is highly modifiable by diet and drugs (table 1). It provides the starting material for faecal microbiota transplantation (FMT) that has been shown to cure patients with recurrent Clostridioides difficile infections and other diseases. ${ }^{11-15}$

It is important to note that we can live without a colon but not without a small intestine that features the largest mucosal surfaces of our body where our food is further digested and taken up, contains most of the gut receptors, immune and nerve cells and is increasingly implied in essential microbe-host crosstalk. While hard to approach experimentally, a variety of new technologies have been developed in recent years, which include catheters or capsules to sample, deliver or inspect. ${ }^{16-18}$ In addition, small intestinal effluent obtained from ileostomies was studied and found to contain up to 100 million microbes per gram wet weight that formed personalised communities, showing day and night rhythms reflecting food intake and processing. ${ }^{19}$ Functional (transcriptomics and targeted metabolomics) and metagenomic analysis of such samples revealed the colonising Streptococcus and Lactobacillus spp to express a large reservoir of highly effective transport systems that compete with the host for sugar uptake and use, generating lactate and acetate that are substrates for Veillonella spp and are converted then into propionate. ${ }^{20}$ Recent studies using specially developed catheters confirmed these 


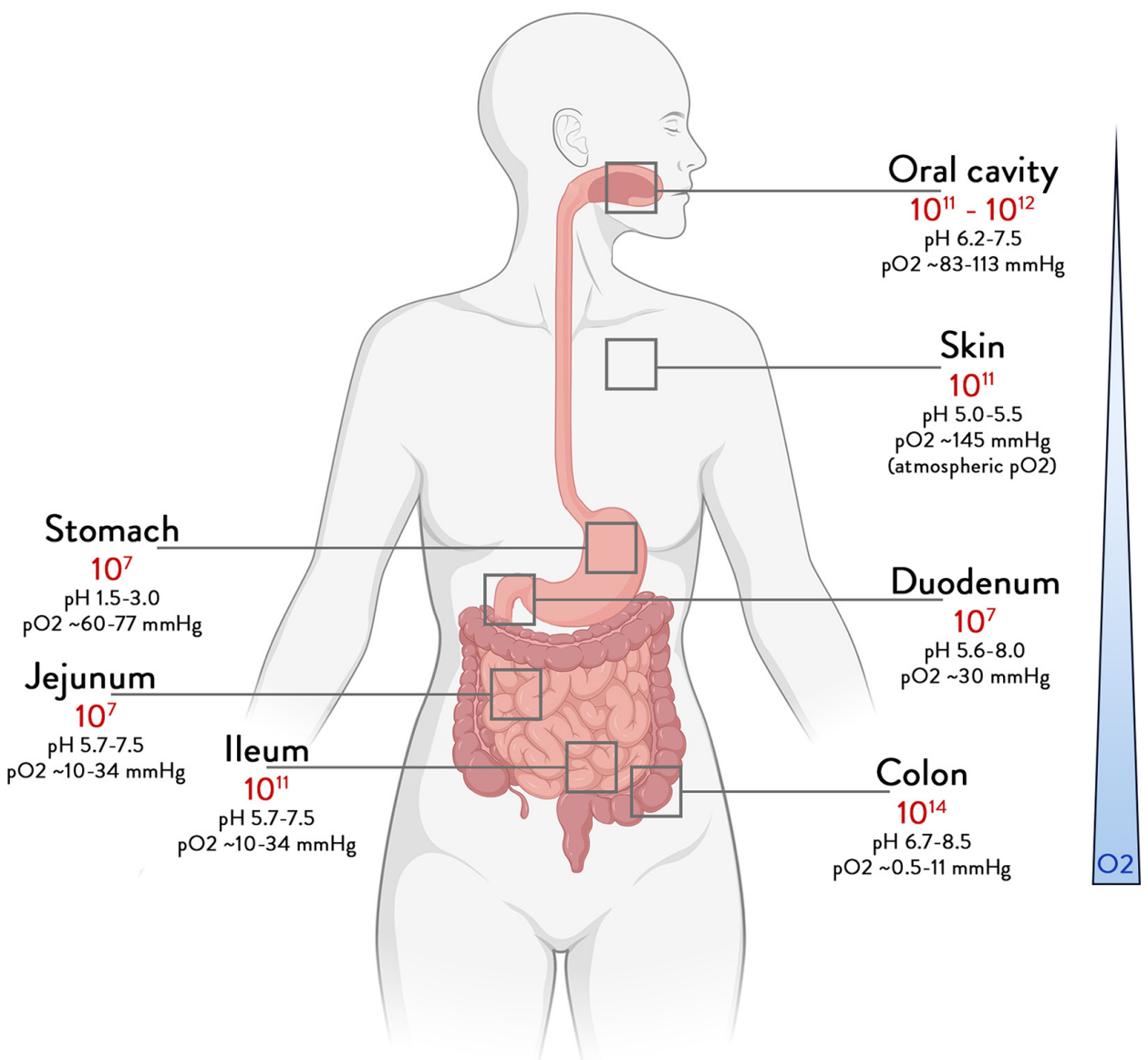

Figure 1 Total abundance of bacteria according to the different body sites. Bounds for bacteria number in different organs, derived from bacterial concentrations and volume. ${ }^{190} 191$

communities and revealed that the duodenal microbiota exhibited higher compositional dynamics correlating with the $\mathrm{pH}$ as compared with the jejunum, which is the intestinal compartment with the largest surface and is responsible for most sugar, protein and lipid digestion and absorption. ${ }^{521}$ While there is a continuum between the duodenum and jejunum, the more proximal ileum has a large mucus layer, reminiscent of the colon, and is colonised with several anaerobes, including members of the Bacteroidia, Ruminococcaceae and Lachnospiraceae, some of which are also implied in BAs transformation (see section bioactive lipids/bile acids). ${ }^{21} 22$

Table 1 PubMed-listed articles regarding topics, "microbiome and diseases"

\begin{tabular}{|c|c|c|}
\hline & PubMed search & PubMed search \\
\hline Diseases & $\begin{array}{l}\text { "disease \& } \\
\text { microbiome" }\end{array}$ & $\begin{array}{l}\text { "disease \& microbiome/ } \\
\text { clinical trial" }\end{array}$ \\
\hline IBDs & 2867 & 36 \\
\hline Coeliac disease & 524 & 20 \\
\hline IBS & 1516 & 96 \\
\hline Colorectal carcinoma & 1525 & 43 \\
\hline Liver disease & 4927 & 113 \\
\hline Pancreatic disease & 766 & 20 \\
\hline Obesity & 7146 & 292 \\
\hline Type 2 diabetes & 2155 & 99 \\
\hline Non-alcoholic fatty liver disease & 1383 & 31 \\
\hline
\end{tabular}

PubMed search 15 December 2021.
The duodenum and its microbes have emerged as a major factor in a variety of metabolic and possibly immune diseases. ${ }^{23}$ Support for this and further new insight derived from duodenal delivery of FMT that alleviated symptoms of metabolic syndrome or autoimmune disease. ${ }^{24-26}$ Moreover, duodenal perfusions of live or dead Lactobacillus spp have been found to affect the host immune response, providing an experimental system for human discovery. ${ }^{27-29}$ This has been recently exploited for the analysis of a single duodenal dose of Anaerobutyricum soehngenii (previously known as Eubacterium hallii) ${ }^{30}$ that increased the duodenal expression level of the gene for regenerating islet-protein $1 \mathrm{~B}$ almost 10-fold and also increased serum glucagon-like peptide-1 (GLP-1) and secondary bile salts in metabolic syndrome subjects, thereby potentially explaining their improved response to glucose. $^{3132}$

Although there is an evident vertical gradient in the gut, a horizontal gradient also exists and has been studied most extensively in the colon. Importantly, there exist oxygen, redox and mucus gradients that starts at the mucosal surface and stretches to the lumen, resulting in architecture of the microbial communities. ${ }^{33}$ Broadly speaking, these start with mucus-degrading consortia that are usually dominated by the mucolytic and microaerophilic Akkermansia muciniphila and end with strictly anaerobic communities, including butyrate-producing and propionate-producing Ruminococcaceae, Lachnospiraceae and Bacteroidia as well as homoacetogens and methanogens that convert hydrogen and carbon dioxide into acetate or methane, respectively. 


\section{THE GUT MICROBIOME AND VARIOUS INTESTINAL AND EXTRAINTESTINAL DISEASES}

The gut microbiome has been associated with several intestinal and extraintestinal disorders. ${ }^{34}$ Many large studies investigating the gut microbiome and its relevance have been performed in specific gastrointestinal (GI) disorders such as intestinal bowel diseases (IBDs), ${ }^{35}$ coeliac disease, ${ }^{36}$ irritable bowel syndrome (IBS), ${ }^{37}$ colorectal cancer (CRC), ${ }^{38}$ chronic liver diseases ${ }^{39}{ }^{40}$ or pancreatic disorders. ${ }^{41}{ }^{42} \mathrm{IBDs}$, prototypic inflammatory disorders of the intestine, are associated with deviating gut microbiome composition and indeed facultative anaerobes outgrow have been reported, especially in the context of active inflammation and metabolite disturbances including BAs, short chain fatty acids (SCFAs) and acylcarnitine pathways. ${ }^{35}$ Longitudinal analysis in infants at risk for coeliac disease, another frequent inflammatory intestinal disorder, demonstrated an increased presence of several microbial species such as Dialister invisus, Parabacteroides spp or Lachnospiraceae and certain metabolites such as tryptophan metabolites before disease onset whereas various anti-inflammatory strains such as Faecalibacterium prausnitzii or Clostridium clostridioforme were decreased. ${ }^{36}$ IBS, a frequent functional disorder of the GI tract, has been associated with IBS subtype-specific changes in the gut microbiome and related metabolites, with purine metabolism being especially affected. ${ }^{37} \mathrm{CRC}$, the most common malignancy in the lower gut, has been convincingly correlated with a disturbed gut microbiome and implicated certain bacteria such as Fusobacterium nucleatum, Escherichia coli or Bacteroides fragilis, some of which are derived from the oral microbiome. ${ }^{38}$ Chronic liver diseases, especially advanced liver diseases such as liver cirrhosis, are characterised by profound microbial aberrations and data from interventional studies with prebiotics, probiotics and antibiotics have well established that the gut microbiome plays a key role in these diseases. ${ }^{40}$ Pancreatic adenocarcinoma, an increasingly recognised malignancy in the Western world, has also been linked to an impaired gut microbiome as intratumoral microbiome composition affects the host immune response and natural history of the disease. ${ }^{42}$

The gut microbiome has been extensively investigated in the past years in obesity and obesity-related disorders such as type 2 diabetes (T2D) and non-alcoholic fatty liver disease (NAFLD). Many studies have tried to link an altered gut microbiome to obesity and indeed interventional studies with certain bacterial strains such as Akkermansia muciniphila have shown effects on obesity-related parameters. ${ }^{43}$ T2D has also been characterised by an impaired gut microbiome in Asian and European populations. ${ }^{445}$ In T2D, microbial variations were strongly correlated with the presence of insulin resistance and several studies implied that the gut microbiome affects glucose regulation. ${ }^{46}$ NAFLD is currently the most common chronic liver disease in the Western world and is considered a prototypic metabolic disorder at the interface of obesity, metabolic syndrome and T2D. There is growing evidence that the gut microbiome-liver axis plays a role in NAFLD, especially in cases of fibrosis and progression towards more advanced disease stages, such as non-alcoholic hepatic steatosis. ${ }^{47}$ Several studies have now demonstrated that NAFLD is characterised by a bloom in certain Enterobacteriaceae, E. coli and a decrease in F. prausnitzii. Recent data also suggest that in NAFLD microbiome deviations and instability may exist over many years and might even precede development of NAFLD and T2D. ${ }^{48}$ There is a growing number of GI and metabolic disorders where the gut microbiome has been investigated (see table 1 for an overview).

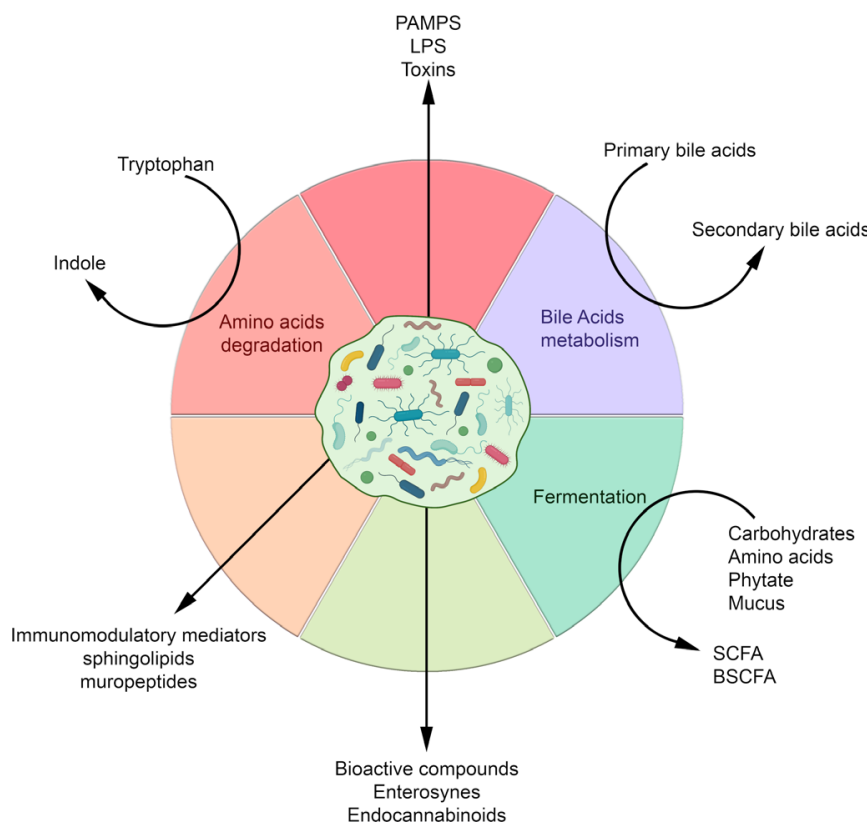

Figure 2 Molecules and metabolites produced by the gut microbiota according to the nutrients or metabolic source and their derived compounds. BSCFA, branched SCFA; LPS, lipopolysaccharides; PAMPs, pathogen-associated molecular patterns; SCFA, short chain fatty acids.

\section{GUT MICROBES AND METABOLIC DISORDERS: MOLECULAR ACTORS}

The gut bacterial community plays an important role in the regulation of multiple aspects of metabolic disorders. This regulation depends, among other things, on the production of a wide variety of metabolites by the microbiota and on their interactions with receptors on host cells that can activate or inhibit signalling pathways, and either be beneficial and detrimental to the host's health (figure 2).

The bacterial metabolites involved in these interactions are very diverse and range from small molecules to large macromolecules. They include by-products of bacterial metabolism, such as SCFAs, and complex macromolecules necessary for bacterial integrity, such as peptidoglycan and lipopolysaccharides (LPS) (figure 2).

The abundance and availability of these metabolites are dependent on the microbial composition and are therefore subject to modulation by diet and environmental factors. ${ }^{49-51}$ The main molecular actors are discussed below.

\section{Short chain fatty acids and impact on host health: molecular mechanisms}

The small intestine is highly specialised in the breakdown, emulsification and absorption of nutrients and few nutrients will escape digestion. In normal conditions, for example, $<5 \mathrm{~g} /$ day of fat will reach the colon. The same principle is true for the digestion and absorption of simple carbohydrates (broken down into sugar molecules) and most proteins (converted into amino acids), although, depending on the level of intake, some proteins will reach the colon. Conversely, complex carbohydrates, such as dietary fibres are non-digestible, meaning that the body lacks the necessary enzymes to digest them allowing them to escape digestion in the small intestine. In the colon, however, they can be used as an energy source by specific resident bacteria. Various 
gut microbes will contribute to the metabolisation of these non-digestible carbohydrates into different SCFAs molecules (eg, acetate, butyrate and propionate). SCFAs are chemically well-characterised and their impact on health has already been extensively documented. ${ }^{52-54}$
These compounds regulate numerous metabolic pathways in the gut and at distance such as in the liver, the adipose tissue, the muscles and the brain (figure 3). ${ }^{55-57}$ Nowadays, these microbial metabolites are known to contribute to numerous physiological effects ranging

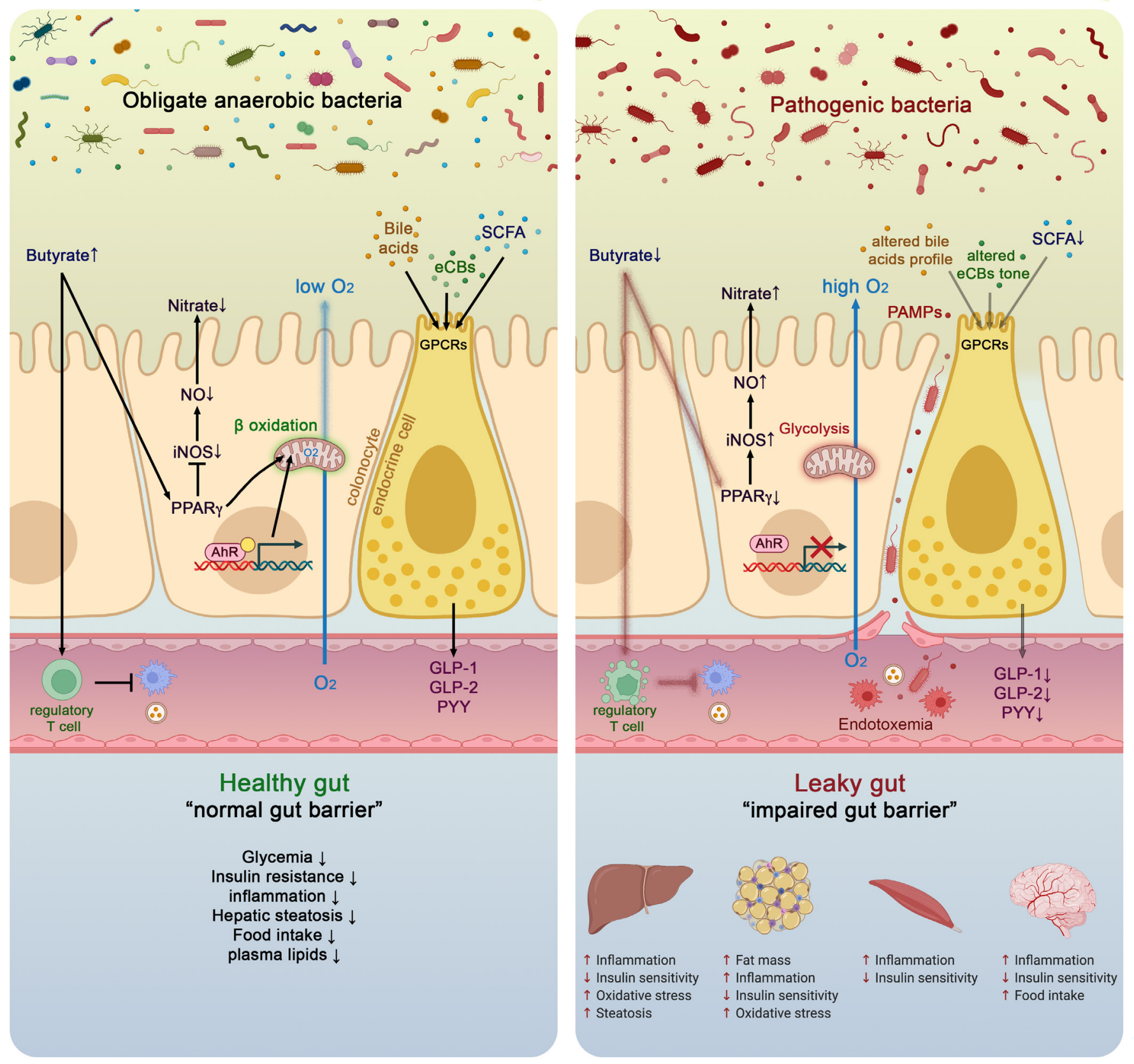

Figure 3 Molecular mechanisms linking gut microbiota and host health in both healthy and pathological situation. In healthy situation, colonocytes use butyrate as energy substrate via the beta-oxidation in the mitochondria, thereby consuming oxygen and directly contributing to maintain anaerobic condition in the lumen. Butyrate also binds to peroxisome proliferator-activated receptor gamma (PPAR $\gamma$ ) which in turn repress inducible nitric oxide synthase (iNOS), decreases nitric oxide production (NO) and eventually nitrate production. Conversely, in pathological situations low butyrate content in the lumen is associated with lower PPAR $\gamma$ activity, increased glycolysis and lower oxygen consumption. This is associated with a higher expression of iNOS which in turn produces more NO and eventually increases nitrates availability for specific pathogens. Butyrate can also stimulate immune cells such as regulatory T cells (Treg) to reduce inflammation. The nuclear transcription factor aryl hydrocarbon receptor (AhR) is highly expressed and activated in healthy colonocytes, whereas agonists of AhR are lower or reduced AhR activity can lead to altered gut barrier function. Enteroendocrine cells (L-cells) are expressing several key receptors activated by short chain fatty acids (SCFAs), specific endocannabinoids (eCBs) and bile acids (BAs). Activating these receptors increase the secretion of key gut peptides such as glucagon-like peptide (GLP)-1, GLP-2 and peptide YY (PYY). Altogether, the interaction between the gut microbes and these molecular actors contributes to reduce intestinal permeability, to improve insulin secretion and insulin sensitivity, to reduce food intake, to lower plasma lipids and to avoid hepatic steatosis and metabolic endotoxaemia. All these effects are associated with lower inflammation. Conversely, opposite effects have been observed in pathological situations. 
from the modulation of energy homeostasis, glucose/ lipid metabolism, inflammation and even immunity and cancer. $^{52}$

Thanks to a series of experimental studies, many of the molecular mechanisms by which a diet enriched with fermentable dietary fibres (eg, prebiotics) are able to decrease body weight gain, fat mass development, insulin resistance and energy intake have been discovered. ${ }^{58-62}$ Among them, it was found that modulating the gut microbiota using prebiotics led to a higher endogenous production (ie, mRNA and peptides) and portal vein secretion of several gut peptides produced by the L-cells such as GLP-1, GLP-2 and peptide YY (PYY) (figure 3). ${ }^{59-61}$ 63-65

These effects are not exclusively limited to one type of fermentable carbohydrates since the microbial fermentation of resistant starches or arabinoxylans into SCFAs produces similar physiological effects linked to increased plasma GLP-1 and PYY levels. ${ }^{66-69}$ However, the chemical structure of the fermentable fibres is directly related to the SCFA production profile since the quantity of butyrate, acetate or propionate generated will depend on the type of fibres. For example, inulin is described as propionogenic, whereas resistant starches are more butyrogenic. Of note, several colonic bacteria use alternative pathways to also produce butyrate from amino acids such as lysine or propionate from plant compounds such as phytate. ${ }^{70}$ It is worth noting that the sources of SCFAs are derived from the diet and they can originate from the host itself via the fermentation of the intestinal mucus that covers the intestinal epithelial cells. ${ }^{72}$

SCFAs stimulate the secretion of gut peptides by acting on specific G-protein-coupled receptors expressed at the surface of the enteroendocrine L-cells that are specifically abundant in the terminal ileum and colon. These receptors, named G protein-coupled receptor (GPR)43 (or free fatty acid receptor 2 (FFAR2)) and GPR41 (or FFAR3) (figure 4), ${ }^{73}$ are also expressed in a wide variety of tissues and cell types (eg, adipocytes, immune cells). ${ }^{74-76}$ The key role played by the microbiome on the secretion of the gut peptides has been elucidated by using mouse models lacking either GPR43 or GPR41. Mice lacking these receptors exhibit reduced secretion of GLP-1 and PYY after exposure to SCFAs or specific prebiotics (figure 3)..$^{77-79}$

In addition to their well-known role and mechanisms of action, some SCFAs might also exert different functions from what has previously been thought. For example, butyrate has been described many times as an essential energy source for the colonic cells to proliferate and maintain the gut barrier. However, recent evidence shows that butyrate also strongly influences the microbial environment by communicating with colonic cells. Indeed, the abundance of oxygen in the luminal part of the gut and its gradually decreasing concentration towards the epithelium is a key requirement for anaerobic bacteria to remain in the close vicinity of the epithelium as opposed to facultative anaerobes such as Enterobacteriaceae (phylum Proteobacteria) that have been shown to increase the risk of intestinal inflammation (figure 3). ${ }^{80} 81$ Butyrate contributes to control of the anaerobic condition in the colon by activating the $\beta$-oxidation in the mitochondria. By activating the nuclear receptor peroxisome proliferator-activated receptor gamma (PPAR $\gamma$ ) in the colonic cells, butyrate limits the diffusion of oxygen from the colonocytes to the luminal part, thereby maintaining the anaerobic conditions. The activation of PPAR $\gamma$ also represses the expression of the gene encoding inducible nitric oxide synthase, thereby reducing NO production and ultimately luminal nitrate levels that are specific energy sources used for the proliferation of putative pathogenic facultative anaerobes (Enterobacteriaceae) (figure 3 ).

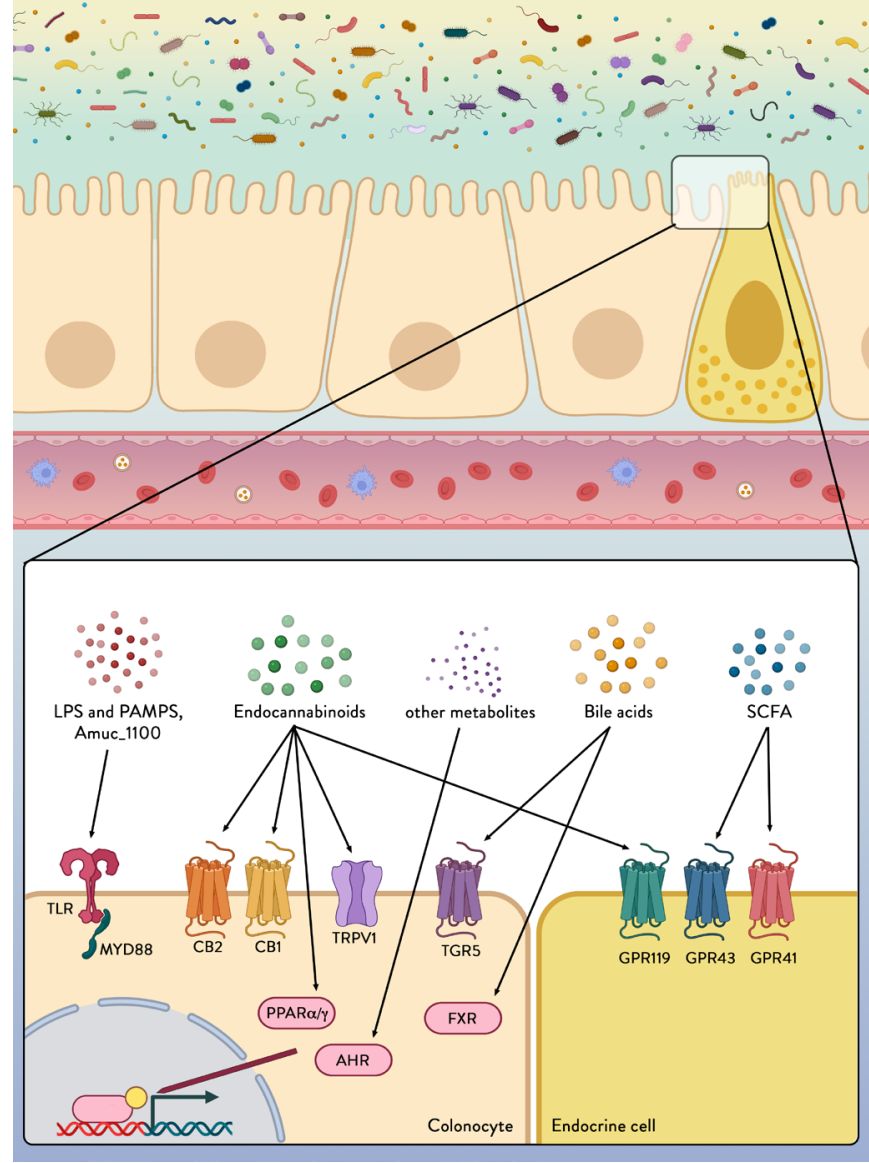

Figure 4 Colonocytes and endocrine cells express a variety of receptors able to sense and transmit signals from the microbial environment. Microbial/Pathogen-associated molecular patterns (PAMPs), lipopolyscaccharides (LPS) from the microbiota are detected by pattern recognition receptors, including toll-like receptors (TLRs). Amuc_1100 is a protein expressed on the outer membrane of Akkermansia muciniphila and which has been shown to signal through TLR2 to improve gut barrier function and reduce inflammation. Metabolites secreted by certain microbes (eg, endocannabinoids (eCBs)), generated by microbial digestion of dietary components (eg, short chain fatty acids (SCFAs)) or by transformation of host-derived factors (eg, eCBs and bile acids) can be sensed through various receptors and pathways to alter intestinal integrity and host health. CB1, CB2, cannabinoid receptor type 1 and type 2; TRPV1, transient receptor potential cation channel subfamily $V$ member 1 ; FXR, farnesoid X receptor; AhR, aryl hydrocarbon receptor; GPR119, GPR43, GPR41, G-protein coupled receptor 119, 43 and 41; MYD88, myeloid differentiation primary response 88; PPAR $\alpha / \gamma$, peroxisome proliferatoractivated receptors alpha and gamma; TGR5, Takeda G protein-coupled receptor 5 .

Similar observations have been done in humans with severe intestinal inflammation, such as during IBD, cancer, obesity and diabetes, ${ }^{52} 82-84$ in which an increased abundance of Enterobacteriaceae has been detected.

Strikingly, numerous papers are pointing to the fact that all these diseases are also associated with a decreased abundance of bacteria that produce SCFAs, mostly propionate and butyrate. ${ }^{85}$ This is the case for instance of the bacteria F. prausnitzii, A. muciniphila and more recently Dysosmobacter welbionis. ${ }^{86} \mathrm{~A}$ specific case is made for Anaerostipes and Anaerobutyricum spp that generate butyrate from lactate in the presence of acetate 
using the acetyl-CoA pathway. ${ }^{87}$ These can form trophic chains in the small intestine as well as the colon where a variety of bacteria produce lactate. Accumulation of lactate, an undesired acid, in the gut environment results in GI disorders, potentially explaining some benefits of interventions with butyrogenic $A$. soehngenii in metabolic syndrome subjects. ${ }^{3288}$

Besides propionate and butyrate, the impact of succinate is also being investigated. Succinate is best known as an intermediate of the Krebs cycle and considered as a substrate for mitochondrial oxidative phosphorylation, but is also a metabolic product from bacteria. In this context, succinate has been classically ignored because it was considered as being mainly a key intermediate in propionate synthesis. Currently, the role of succinate remains largely a matter of debate ${ }^{89}$ as there have been reports of both beneficial and opposite associations between succinate and insulin resistance, obesity and inflammation. ${ }^{90-93}$

\section{Lipopolyscaccharides/Pathogen-associated molecular patterns} The gut barrier is a complex and dynamic collection of physical and chemical structures that surveil the environment and protects the host from microbial invaders and harmful stimuli. Some of these hazardous components coming from the environment are the so-called pathogen-associated molecular patterns (PAMPs), of which bacterial LPS are the prototypical class. ${ }^{94}$

LPS, endotoxins found on the cell membranes of Gramnegative bacteria, are potent activators of the inflammatory response and release of even small amounts of LPS into the circulation are sufficient to elicit an inflammatory response.

LPS and other PAMPs exert their activity through activation of specific pattern recognition receptors (PRRs) that sense microorganisms and infectious agents and signal a defensive response. There are four major subfamilies of PRRs: the toll-like receptors (TLRs), the nucleotide-binding oligomerisation domainleucine-rich repeats (LRR)-containing receptors, the retinoic acid-inducible gene 1 (RIG-1)-like receptors (aka RIG-1-like helicases) and the C-type lectin receptors. ${ }^{95}$ Among those the TLRs, a family of receptors comprising 10 members in human (13 in mice), are the best characterised. Each of the TLRs mediates responses to distinct microbial components derived from pathogens. Two typical examples are TLR2, which senses bacterial lipoproteins, ${ }^{96}$ and TLR4, which recognises bacterial LPS. ${ }^{97}$ Together the TLRs cover a wide range of both external stimuli (PAMPs) ${ }^{98}$ and internal signals derived from tissue damage (damage-associated molecular patterns (DAMPs)) (figures 3 and 4). ${ }^{99}$ These ligands come in many forms and sizes: from nucleic acids to lipids, from small compounds to macromolecules. TLRs are widely distributed in immune cells including macrophages, neutrophils, dendritic cells, natural killer cells, mast cells, basophils and eosinophils, ${ }^{99}$ but also in other body cells, such as intestinal epithelial cells. Their activation induces antigenpresenting cell activation, thereby bridging the innate and the adaptive immune responses, and stimulates signalling cascades as an attempt to fend off microbial invaders or repair the damaged tissue. Although this inflammatory response is required to eliminate the infection, excessive activation of TLRs can lead to disruption of immune homeostasis and the sustained proinflammatory cytokines and chemokine production can increase the risk of inflammatory diseases and autoimmune disorders. This is the case in metabolic endotoxaemia, in which high-fat diet and weight gain have been associated with a higher gut permeability and subsequent systemic (mild) elevation in circulating plasma LPS. ${ }^{100}$ This causes a state of low-grade inflammation, which is a pathological feature of a range of chronic conditions including T2D, NAFLD, chronic kidney disease and atherosclerosis. $^{3839101102}$ Interestingly, LPS from different types of bacteria have distinct effects on gut-barrier function, adipose inflammation, intestinal glucose absorption, blood glucose, insulin and incretins, indicating that the net effect of metabolic endotoxaemia levels on host metabolism can vary in function of gut microbiota composition. ${ }^{103}$

Disruption of PRRs expression has been associated with alterations in the microbiota composition that favour inflammation. For example, mice deficient in TLR5, which is activated by bacterial flagellin, develop colitis or metabolic syndrome, associated with an altered microbiota. ${ }^{104} 105$

The TLR activation of downstream signalling pathways has been shown to be dependent on myeloid differentiation factor 88 protein (MyD88) (figure 4). MyD88 is an essential adaptor protein for all TLRs, except TLR $3^{106}$ and deletion of MyD88 in the intestines partially protects against diet-induced obesity, diabetes and inflammation and increases anti-inflammatory endocannabinoids (eCBs), restores antimicrobial peptides production and increases intestinal regulatory $\mathrm{T}$ cells during diet-induced obesity. ${ }^{107}$

Although many questions remain to be answered before we have a full understanding of how PAMS/DAMPS, PRRs, the microbiome and disease state interact, our growing understanding of this complex interplay is opening new therapeutic possibilities for inflammation-dependent disorders.

\section{Bioactive lipids}

\section{Endocannabinoid system}

Over the last two decades, the eCB system has been widely explored because of its extensive range of physiological effects. Among its pleiotropic effects, the eCB signalling system appears to play a key role in regulating energy, glucose and lipid metabolism but also in immunity, inflammation and more recently in microbiota-host interactions. ${ }^{108109}$

Historically, it was in 1988 that the first endogenous cannabinoid receptor type $1\left(\mathrm{CB}_{1}\right)$ was identified as being activated by the psychoactive compound of Cannabis sativa, $\Delta 9$-tetrahydrocannabinol, ${ }^{110}$ followed by the discovery of a second receptor in 1993, the cannabinoid receptor type $2\left(\mathrm{CB}_{2}\right) .{ }^{111}$ Both receptors are GPRs and share common signalling mechanisms. ${ }^{112}$ The first endogenous agonist identified was anandamide ( $\mathrm{N}$-arachidonoylethanolamide (AEA)). AEA is one of the key members of a large group of bioactive lipids that belong to the $\mathrm{N}$-acylethanolamine (NAE) family. ${ }^{113}$ The second key ligand identified was 2-arachidonoylglycerol (2-AG). ${ }^{114}$ Since the discovery of these two major compounds, the eCB family has been expanded and is no longer restricted to only eCBs with specific activity on $\mathrm{CB}$ and $\mathrm{CB}_{2}$ receptors. For example, some eCBs also interact with $\operatorname{PPAR} \alpha$ and PPAR $\gamma$, as well as with other membrane receptors such as GPR55, or transient receptor potential vanilloid type-1 (TRPV1) (figure 4). Besides the so-called 'true' eCBs, that is, eCBs able to bind $\mathrm{CB}_{1}$ and $\mathrm{CB}_{2}$, numerous other compounds with structural resemblance to the prototypical eCBs have been shown to interfere with the eCB response without directly activating $\mathrm{CB}_{1}$ or $\mathrm{CB}_{2} \mathrm{eCB}$ receptors. All these molecules are referred to as eCB-like compounds or congeners and are bioactive lipids including other NAEs or members of the acylglycerol family. ${ }^{115116}$ However, eCB-like compounds can also exert pharmacological activity of their own. For example, $\mathrm{N}$-oleoylethanolamine (OEA) or N-palmitoylethanolamine (PEA) can activate PPAR $\alpha$ and TRPV1, and OEA, N-linoleylethanolamine (LEA) and 2-oleoylglycerol (2-OG) are able to activate GPR119. ${ }^{117}$ 
More recently, it was shown that both 1-palmitoylglycerol (1-PG) and 2-palmitoylglycerol (2-PG) are PPAR $\alpha$ agonists (figure 4). ${ }^{118}$

In 2010, it was discovered that among the metabolic systems involved in the regulation of the gut barrier function the $\mathrm{eCB}$ system was playing a major role. ${ }^{108}$ It began with the finding that the intestinal eCB system is altered during obesity and diabetes, with an increased abundance of AEA that triggers gut permeability via $\mathrm{CB}_{1}$-dependent mechanisms. ${ }^{108}$ Interestingly, this modification of the eCB system tone was associated with changes in the gut microbiota. Moreover, pharmacological activation of the $\mathrm{eCB}$ system with a potent $\mathrm{eCB}$ agonist increased adipogenesis and disrupted the gut barrier. ${ }^{119}$ In a series of independent studies, the link between gut microbiota, adipose tissue metabolism and the eCB system has been confirmed since both genetically obese and diabetic mice $(o b / o b$ and $d b / d b)$ present a profound shift in their gut microbiota composition, which is associated with altered whole body tissue metabolism and $\mathrm{eCB}$ system tone. ${ }^{120} 121$ Taken together, these data strongly support a link between specific bioactive lipids, belonging to the eСB system, and the gut microbiota, the development of the adipose tissue and intestinal function.

To further explore the underlying mechanisms and to demonstrate whether the synthesis of these NAEs could be involved in the onset of metabolic disorders and changes in the gut microbiota, several mouse models have been generated in which $\mathrm{N}$-acylphosphatidylethanolamine-hydrolysing-specific phospholipase D (NAPE-PLD), a key synthesis enzyme, has been inactivated in either adipocytes, intestinal epithelial cells or hepatocytes. ${ }^{122-125}$

Mice lacking NAPE-PLD in adipocytes spontaneously developed obesity, insulin resistance and inflammation on a normal caloric diet and were more sensitive to high-fat diet-induced metabolic disorders. ${ }^{122}$ The adipocyte-specific deletion of NAPE-PLD decreased the thermogenic programme (ie, browning/beiging) in adipose tissue and resulted in a profound shift in the gut microbiota composition. Moreover, transferring the microbiota from adipose tissue NAPE-PLD deleted mice to germ-free recipient mice replicated the overall phenotype, ${ }^{122}$ suggesting a causal role of the gut microbiota. When deleting NAPE-PLD in intestinal epithelial cells, a different phenotype occurred. Mice became hyperphagic on first exposure to a high-fat diet and then developed exacerbated diet-induced obesity and hepatic steatosis. Mechanistically, this was attributed to a defect in the gut-tobrain axis, as hypothalamic Pomc neurons alterations were found, likely explained by changes in both intestinal and plasma eCBs. Strikingly, the gut microbiota was also affected in this model and modulating the microbiota could partially revert the phenotype. ${ }^{123}$ In the last model, mice deleted for the NAPE-PLD in the hepatocyte developed a high-fat diet-like phenotype under normal diet (ie, increased fat mass gain, hepatic steatosis, liver inflammation). These effects were related to changes in other key bioactive lipids known to be influenced by the gut microbiota such as BAs. ${ }^{124}$ Collectively, all these data and animal models suggest that the eCB system, through the NAPE-PLD, is dialoguing with the gut microbiota via the production of bioactive lipids, and it turn any dysregulation of this enzyme can lead to metabolic complications.

To further explore the potential links between the gut microbiota and the regulation of the eCB system, the endocannabinoidome (eCBome) of germ-free mice was compared with that of conventionalised mice at different time-points. The eCBome is an extension of the eCB system that comprises over 50 receptors and metabolic enzymes, and $>20$ lipid mediators with important functions. ${ }^{126}$ An age-dependent modification in intestinal
eCBome gene expression and lipid mediator levels was found. Strikingly, faecal material transplantation from control mice donors to age-matched germ-free mice reversed several of these alterations, already after only 1 week. ${ }^{126}$ Altogether, this set of studies demonstrate that the gut microbiota is directly impacting the host eCBome.

In conclusion, all evidence points towards a bidirectional cross-talk between the host's eCB system and the gut microbiota. However, further investigations are warranted to untangle the many remaining mysteries of this relationship. Adding to the complexity, it has recently been shown that the gut microbiota itself is able to produce specific eCBs. ${ }^{127}$ This opens new exiting opportunities of exploring the microbiota to host interaction and offers several novel putative targets for therapy.

\section{Bile acids}

Primary BAs, such as cholic acid (CA) and chenodeoxycholic acid (CDCA) in humans (and muricholic acid (MCA) in rodents), are amphipathic molecules synthesised in the liver from cholesterol. ${ }^{128}$ They can be conjugated to glycine or taurine prior to their secretion into bile and storage in the gallbladder. When food is ingested, BAs are released into the small intestine where they assist in the digestion and absorption of dietary fat. Around $95 \%$ of intestinal BAs are reabsorbed in the ileum to return to the liver for re-secretion. This enterohepatic circulation of BAs occurs several times a day and is an important physiological mechanism for maintaining whole body glucose, lipid and energy homeostasis to prevent hyperglycaemia, dyslipidaemia and obesity, and it protects against inflammatory metabolic diseases of the digestive and cardiovascular systems. ${ }^{129}$ Only a small fraction of the BAs will escape this highly efficient loop and reach the colon. These BAs are then either reabsorbed passively into the circulation or excreted via the faeces. The losses in BAs are compensated by de novo hepatic synthesis, which is regulated by fibroblast growth factor-19 (FGF19) in humans signalling in the small intestine (FGF15 in rodents).

Although the primary function of BAs is to regulate the digestion and absorption of cholesterol, triglycerides and fat-soluble vitamins, it has been recently recognised that BAs also serve an endocrine function as they act as signalling molecules. Moreover, BAs have been shown to modulate epithelial cell proliferation, gene expression, lipid, glucose and energy metabolism by activating several receptors. These receptors are the vitamin $\mathrm{D}$ receptor, ${ }^{130}$ pregnane $\mathrm{X}$ receptor, ${ }^{131}$ constitutive androstane receptor, ${ }^{132}$ farnesoid X receptor and G-protein-coupled bile acid receptor-1 (also known as Takeda G protein-coupled receptor 5 (TGR5)) (figure 4). These receptors are present in numerous tissues including the liver, intestine, muscle, brown adipose tissue and central and peripheral nervous systems and mediate the signalling cascade and activate expression of genes involved in the metabolism of BA, lipids and carbohydrates and in energy expenditure and inflammation. Signalling through FXR and TGR5 receptors has also been linked to the secretion of GI hormones such as PYY and GLP-1 (figures 3 and 4), known to be integral to the maintenance of energy and metabolic homeostasis. The role of BAs in the control of glucose, lipid and energy metabolism has been reviewed previously 128133134 and will therefore not be reviewed in detail here.

Primary BAs are susceptible to be modified by gut microbes all along the intestinal tract. These modifications include deconjugation (the removal of amino acid residues) via bile salt hydrolase (BSH) activity and further metabolisation via removal of hydroxyl groups (dehydroxylation), oxidation (dehydrogenation) or 
epimerisation. ${ }^{135} 136$ This results in the formation of secondary BAs such as deoxycholic acid, lithocholic acid and ursodeoxycholic acid (a secondary BA in humans, although a primary BA in rodents). This bacterial metabolism changes the bioavailability and bioactivities of BAs, and consequently their impact on the metabolic responses they are involved in. ${ }^{137}$ Because of their signalling capacities and the fact that BAs are chemically transformed by the gut microbiota, BAs can therefore be considered as microbiota-derived signalling metabolites. Interestingly, there is a spatio-temporal pattern to be recognised as BAs are released after food intake and then encounter different microbial communities along the intestinal tract. While BSH activity can be carried out by a wide variety of bacteria distributed among many phylogenetically different bacterial divisions, including species able to colonise the small intestine, ${ }^{138}$ the other reactions are thought to be more restricted to more specialised bacterial species that reside in the distal part of the gut. Therefore, to fully understand the role of the gut microbiota on host metabolism, it is essential to study the involvement of the different bacteria capable of converting BAs. A recent study in centenarians suggested that their specific gut microbiota signatures may partially account for their decreased susceptibility to ageingassociated illnesses, chronic inflammation and infectious diseases by generating unique secondary BAs. This implies that manipulating the BA pool via modulation of the gut microbiota composition could represent a feasible way to combat diseases. ${ }^{139}$

\section{Aryl hydrocarbon receptor: a link to energy metabolism, inflammation and gut microbiome}

The aryl hydrocarbon receptor (AhR) is expressed ubiquitously in vertebrate cells and this transcription factor is activated after ligand binding. Numerous AhR ligands exist including environmental triggers, nutrition-derived signals, various phytochemicals and bacterial metabolites such as tryptophan (figure 2). AhR ligand binding results in translocation of the AhR into the nucleus where it is bound to its dimerisation molecule AhR nuclear translocator resulting in the transcription of numerous genes involved in immunity and inflammatory processes (figure 3). Bacterial products and metabolites play a key role as activators and therefore several reports from the past years have tried to figure out the interplay of AhR with the gut microbiota (figures 3 and 4). ${ }^{48} 140$ Importantly, this AhR pathway has also been linked to energy metabolism and metabolic syndrome as there exists a reduced capacity both in preclinical and clinical settings of metabolising tryptophan into AhR binding derivates in metabolic syndrome. ${ }^{141}$ These authors showed that an increase of AhR ligands achieved by the administration of a Lactobacillus strain improved metabolic functions paralleled by ameliorated intestinal barrier and reduced hepatic steatosis. Indigo, a naturally occurring AhR ligand with potent antiinflammatory activities, protects against high-fat diet-induced obesity and metabolic disturbances by upregulation of Lactobacillus spp and the key barrier cytokines interleukin (IL)-10 and IL-22. ${ }^{142}$ Microbial tryptophan metabolites such as indole3-ethanol, indole-3-pyruvate and indole-3-aldehyde protect the gut epithelial barrier by affecting the integrity of the apical junctional complex including myosin IIA and ezrin. ${ }^{143}$ In experimental alcoholic liver disease, a disease where the gut microbiome is substantially impaired, ${ }^{144}$ induction of AhR ligands and administration of 6 -formylindolo $(3,2-b)$ carbazole (Ficz) improved alcoholic liver disease. ${ }^{145}$ Caspase recruitment domain family member $9^{-/-}$mice are more susceptible to colitis and their microbiota fail to metabolise tryptophan to its respective metabolites. ${ }^{146}$ Transfer of this microbiota into wild-type mice increases colitis and can be improved by treatment with Lactobacillus strains delivering high amounts of AhR ligands. The AhR pathway might have also major implications for other inflammatory GI disorders such as coeliac disease. ${ }^{147}$ Patients with active coeliac disease show reduced AhR ligand production in their gut compared with non-coeliac control subjects and furthermore in non-obese diabetic mice expressing DQ8 (a transgenic mice that carry only human MHC class II DQ8), a high-tryptophan diet, treatment with Limosilactobacillus reuteri, a bacterial strain producing large amounts of AhR ligands or treatment with the AhR ligand Ficz decreased intestinal pathologies after gluten exposure. ${ }^{147}$ Germ-free mice show an impaired differentiation and repair of the epidermal barrier and mice lacking AhR in keratinocytes specifically are highly susceptible to cutaneous infections and barrier damage and colonisation with a defined group of bacteria restored the barrier. It remains to be established in this model which role intestinal bacteria might play in a putative gut-skin axis. ${ }^{148}$ The AhR pathway therefore reflects a prototypic pathway at the interface microbiota-epithelial barriermetabolism and immune functions.

\section{Key bacteria and their specific molecules}

Most signalling metabolites can be produced by large numbers of different gut bacteria, and hence have limited specificity. However, various bacteria can make specific molecules that have unique interactions with the host (figures 2-4). For obvious reasons, these have been very well characterised in pathogens that can make specific toxins, synthesise polysaccharides to evade the immune system or induce the host to synthesise receptors, allowing them to invade. However, recent research has identified new and unique host signalling molecules that are found in potentially symbiotic gut bacteria. These include immunomodulatory polysaccharides and sphingolipids produced by Bacteroides spp ${ }^{149150}$ and muropeptides formed by Enterococcus spp. ${ }^{151}$

A special class of unique molecules formed are proteins that are genetically encoded by one or a few strains of the same species. Some have been studied in detail and often involve stable or post-translationally modified proteins that have the potential to interact with host receptors as they are secreted, or cell envelope located. Some of these derived from bacteria that are already widely marketed as probiotics, including L. acidophilus NCFM that produces a large, likely glycosylated surface layer protein signalling to the DC-SIGN receptor, ${ }^{152}$ the $90 \mathrm{kDa}$ pilus protein $\mathrm{SpaC}$ of $L$. rhamnosus GG that is a partly glycosylated mucus-binding protein with unusual signalling capacity to DC-SIGN receptor on dendritic cells ${ }^{152} 153$ and the piluslocated Tad protein found in some Bifidobacterium spp that promotes colonic persistence and epithelial proliferation. ${ }^{154} 155$ A recently studied protein is the caseinolytic protease $\mathrm{B}(\mathrm{ClpB})$ of $E$. coli that is an antigen-mimetic of alpha-melanocytestimulating hormone and increases satiety via increased plasma GLP-1 and PYY production. ${ }^{156} \mathrm{ClpB}$ proteins are well-known moonlighting proteins found to be partially secreted by a variety of bacteria, including Lactobacilli and Bifidobacteria. The specificity of $\mathrm{ClpB}$, however, may be not so high as a ClpB-producing Hafnia alvei was also found to suppress satiety to some extent in a human trial. ${ }^{157}$

Considering the effectiveness of live and pasteurised $A$. muciniphila administration in a proof-of-principle human trial, ${ }^{43} 118158$ it is not surprising that several proteins from $A$. muciniphila have recently been identified with potential signalling 
capacity. A recent one is an $84 \mathrm{kDa}$ protein (encoded by the Amuc_1831 gene) termed P9, which after oral administration was found to induce serum GLP-1 in mice. In vitro studies indicated that P9 interacts with the intercellular adhesion molecule 2 receptor. ${ }^{159} 160$ Another recently discovered protein identified is the A. muciniphila $50 \mathrm{kDa}$ Amuc_1434* protein that was found to suppress LS174T cell viability via tumour-necrosis-factorrelated apoptosis-inducing ligand (TRAIL)-mediated apoptosis pathway. ${ }^{161}$ However, both of these proteins are found in many bacteria other than A. muciniphila, both are annotated as proteases suggesting enzymatic activity, and both have not been localised outside the cells, not excluding the possibility that cell lysis is needed for their activity. Even more importantly, their stability has not been addressed, which is of interest as pasteurised $A$. muciniphila cells were as effective or even more than live cells both in human and mice models. ${ }^{43} 162163$ All these arguments do not apply to the other A. muciniphila protein that was discovered to be signalling to TLR2 (figure 4). ${ }^{163}$ This is the $30 \mathrm{kDa}$ Amuc_1100 protein that has been defined as an outer membrane protein with virtually no homology to other bacteria outside the Verrucomicrobia and in fact is suggested to be a pilus-associated protein. ${ }^{164}$ Further studies showed Amuc_1100 to be thermostable and preventing diet-induced obesity in a mouse model. ${ }^{163}$ When comparing all three proteins for their absolute abundance, it is evident that Amuc_1100 is much more abundant than the other two signalling candidates in proteomes of A. muciniphila grown on mucin. ${ }^{165}$ Hence, future comparative studies should determine which proteins or combinations thereof can explain the observed activity of A. muciniphila in humans.

\section{Newly identified molecules, impact on health and their targets}

Besides the classical molecules such as SCFAs, BAs or PAMPs and gut peptides (ie, GLP-1, PYY), all described as regulators of the host metabolism, gut barrier and inflammation, the role of a novel class of molecules called 'enterosynes' is emerging. The concept of enterosynes has been recently introduced and defined as 'molecules originating from the gut which have the capacity to modulate duodenal contraction by targeting the enteric nervous system (ENS). Enterosynes can be chemically diverse and related to hormones, bioactive peptides/lipids, nutrients, microbiota and immune factors ${ }^{166}$

The origin of this concept is based on the observation that subjects with T2D are characterised by a duodenal hypermotility which favours glucose absorption and contributes to hyperglycaemia. ${ }^{166}{ }^{167}$ It has been demonstrated that duodenal contractions are sensed by the hypothalamus ${ }^{167-170}$ and that during diabetes the duodenal hypermotility creates aberrant afferent nervous messages to the brain. ${ }^{169} 171$ Conversely, restoring natural duodenal contraction by acting on ENS neurons restores the gut-brain axis and improves insulin sensitivity. ${ }^{166}$

The connections between gut microbiome, brain function and glucose metabolism are becoming a hot topic in this area of research and the role of the ENS emerged as a new target to tackle diseases such as diabetes. Although various papers are discussing strategies to modulate the gut microbiome, such as probiotics, prebiotics and faecal transplants, in view of alleviating features of metabolic syndrome, few, if not none, of them are characterising intestinal actors such as enterosynes.

In search of novel gut molecules and receptors involved in glucose metabolism, the action of specific fibres known to change the gut microbiota and improve diabetes was explored. The administration of oligofructose decreased duodenal contraction frequency by controlling enteric neurons activity. This led to reduced hyperglycaemia and decreased inflammatory markers in the adipose tissue of the diabetic mice. ${ }^{170}$ By using lipidomic analysis, it was discovered that this oligofructose feeding selectively increased the abundance of an intestinal bioactive lipid (12-hydroxyeicosatetraenoic acid (12-HETE)) in the colonic cells. Strikingly, the administration of 12-HETE to diabetic mice improved glucose metabolism. The effect of 12-HETE was also confirmed ex vivo. Furthermore, they discovered that the molecular mechanism by which this bioactive lipid acts on duodenal contractility is dependent on the presence of the mu-opioid receptors (MOR) (activated by enkephalin) and PPAR $\gamma$. The preclinical findings were supported by human data showing a reduction in the levels of 12-HETE and a decreased expression of the proenkephalin and MOR in the duodenum of patients with diabetes as compared with healthy subjects. ${ }^{170}$

Using various approaches with dietary supplements to tackle IBDs, new bioactive lipids with anti-inflammatory properties were identified. ${ }^{172}$ Exploiting mass spectrometry of the E. coli Nissle 1917 (EcN), a well-studied strain marketed as a probiotic for the treatment of colitis, led to the discovery that the concentration of 3-hydroxyoctadecaenoic acid (C18-3OH) was increased. They found that oral administration of $\mathrm{C} 18-3 \mathrm{OH}$ decreased colitis. To determine whether other bacteria present in the gut microbiota produce $\mathrm{C} 18-3 \mathrm{OH}$, the gut microbiota was modulated by using oligofructose. The authors found that the anti-inflammatory properties of oligofructose were associated with an increase in colonic $\mathrm{C} 18-3 \mathrm{OH}$ concentration. Finally, they identified specific bacteria producing this bioactive lipid and discovered that $\mathrm{C} 18-3 \mathrm{OH}$ acts by activating PPAR $\gamma .{ }^{172}$

Altogether, these two examples show that the gut microbiota is the source of putative numerous bioactive compounds (figure 2) acting on host receptors involved in the regulation of metabolism and inflammation (figure 3).

Whereas some metabolites are desired for health, others may be harmful, but evidence only derives from association studies or animal testing. Three metabolites with negative impact have been subject to recent studies, including fructoselysine, an advanced glycation end product (AGE), trimethylamine $\mathrm{N}$-oxide (TMAO) and imidazole propionate (IMP).

AGEs are Maillard reaction products formed in our foods by thermal processing when free amino groups of proteins and amino acids react with reducing carbohydrates, forming compounds that are poorly bioavailable. A body of mechanistic evidence has linked AGEs to T2D and CRC through stimulation of the pro-inflammatory response via the activation of the receptor of AGEs, ${ }^{173} 174$ an increase in gut permeabilityallowing closer interaction of AGEs with colonic epitheliumand consequential leakage of bacterial toxins into the systemic circulation. ${ }^{175}$ Fructoselysine is an Amadori product formed from lysine and glucose that is one of the primary dietary AGEs. Earlier studies showed that E. coli has the capacity to respire fructoselysine. ${ }^{176}$ However, recent analysis showed that it can be converted into butyrate by members of the genus Intestinimonas spp via a novel pathway. ${ }^{70}$ Of note, the capability to degrade fructoselysine was experimentally and computationally only observed in formula-fed but not in breast-fed infants, which may relate to high contents of this compound in formulas after thermal treatment. ${ }^{177}$ Further studies should address the causality of fructoselysine and other AGEs in T2D and other diseases and the involvement of intestinal bacteria in their conversion. A recent study also described the complete utilisation of $\mathrm{N}-\varepsilon$-carboxymethyllysine, another major AGE, by Cloacibacillus and potentially Oscillibacter spp. ${ }^{178}$ 
TMAO is related to the intake of quaternary amines, such as betaine, choline and L-carnitine, which are commonly found in vegetables, fruits, meat and seafood and are well-known bacterial osmoprotectants. ${ }^{179} 180$ Several gut bacteria including several Proteobacteria can convert these quaternary ammonium ions via TMA lyase and its activating enzyme (CutCD) into acetaldehyde and trimethylamine (TMA). TMA then can enter the bloodstream and is converted by flavin monooxygenase in the liver to TMAO. Recent studies have shown that TMAO in serum is strongly associated with atherosclerosis and cardiovascular risks. ${ }^{181}$ In addition, TMAO has been shown to promote formation of atherosclerotic plaques in a mouse model. ${ }^{182}$ Moreover, TMAO is a common uraemic toxin. ${ }^{183}$ Hence, there is considerable interest in understanding the metabolism of these quaternary ammonium ions into compounds that do not lead to TMA or other TMAO precursors. New insight has come from the biochemical and pathway analysis of Eubacterium limosum and its related gut isolate E. maltosivorans that were found to deaminate betaine and other quaternary amines in a novel process involving bacterial cell compartments and leading to the production of acetate and butyrate. ${ }^{184-186}$ While the latter bacteria are highly related and appear to have a unique vitamin $\mathrm{B}_{12}{ }^{-}$ dependent metabolic pathway, this does not hold for the metabolism of histidine that may lead to the production of IMP. It has been shown that concentration of IMP was increased in the serum of patients with T2D. ${ }^{187}$ It was recently found that IMP is produced from histidine by intestinal bacteria that impaired insulin signalling and glucose tolerance through the mammalian target of rapamycin complex 1-dependent pathway. ${ }^{188}$ Two unrelated bacteria, Streptococcus mutans and Eggerthella lenta have been identified as IMP producers, confirming the fact that many metabolites are produced by several groups of intestinal bacteria that may not share any phylogenetic relations. Altogether, these examples indicate the involvement of intestinal bacteria in generating undesired compounds but identified also new anaerobes that may detoxify these and even convert these in products such as butyrate that have beneficial signalling potential (figures 2 and 3).

\section{GENERAL CONCLUSION AND PERSPECTIVES}

Over the last two decades, considerable progress has been achieved. From initial clinical observations to more mechanistic approaches, the field of gut microbiota and health is evolving to irrefutable causal links. However, there are still numerous studies that claim causality when in fact only correlations are being demonstrated. Moving from correlation to causality remains an important and required step to better design putative interventions based on the modulation of the gut microbiota or by using specific active compounds. ${ }^{50189}$ Thanks to the numerous efforts and the advance in omics analysis, the scientific community is gradually moving towards personalised medicine and the microbiome era is clearly an important part of the paradigm shift in the future of medicine and nutritional approaches.

Correction notice This article has been corrected since it published Online First. Figure 3 has been enlarged.

Twitter Matthias Van Hul @matthias_vanhul and Patrice D Cani @MicrObesity

Contributors PDC has prepared a proposal on the conception of the overall content of the manuscript. PDC, HT, WMdV and MVH have revised, amended and approved the proposal. PDC, HT, WMdV and MVH have collected content, selected the key references, written and critically reviewed the content of the manuscript. PDC and MVH have prepared the figures. PDC, HT, WMdV and MVH have all revised the final version of the manuscript. PDC, HT, WMdV and MVH contributed equally to this paper.
Funding PDC is research director at FRS-FNRS (Fonds de la Recherche Scientifique) and the recipient of grants from FNRS (Projet de Recherche PDR-convention: FNRS T.0030.21, CDR-convention: J.0027.22, FRFS-WELBIO: WELBIO-CR-2017C-02E, WELBIO-CR-2019C-02R, EOS: program no. 30770923 and EOS program no. 40007505). WMDV was supported by the SIAM Gravitation Grant (024.002.002) of the Netherlands Organization for Scientific Research. HT is supported by the excellence initiative VASCage (Centre for Promoting Vascular Health in the Ageing Community), an R\&D K-Centre (COMET program-Competence Centers for Excellent Technologies) funded by the Austrian Ministry for Transport, Innovation and Technology, the Austrian Ministry for Digital and Economic Affairs and the federal states Tyrol, Salzburg and Vienna.

Competing interests PDC and WMdV are inventors on patent applications dealing with the use of Akkermansia muciniphila and its components in the treatment of metabolic disorders. PDC and WMdV are co-founders of A-Mansia Biotech. PDC is co-founder of Enterosys. WMdV is co-founder of Caelus Health and inventor on patents on the use of Eubacterium hallii.

Patient consent for publication Not applicable.

Ethics approval This study does not involve human participants.

Provenance and peer review Commissioned; internally peer reviewed.

Open access This is an open access article distributed in accordance with the Creative Commons Attribution 4.0 Unported (CC BY 4.0) license, which permits others to copy, redistribute, remix, transform and build upon this work for any purpose, provided the original work is properly cited, a link to the licence is given, and indication of whether changes were made. See: https://creativecommons.org/ licenses/by/4.0/.

\section{ORCID iDs}

Willem M de Vos http://orcid.org/0000-0002-0273-3166

Herbert Tilg http://orcid.org/0000-0002-4235-2579

Matthias Van Hul http://orcid.org/0000-0002-5503-107X

Patrice D Cani http://orcid.org/0000-0003-2040-2448

\section{REFERENCES}

1 Korpela K, de Vos WM. Early life colonization of the human gut: microbes matter everywhere. Curr Opin Microbiol 2018;44:70-8.

2 Korpela K, Helve 0, Kolho K-L, et al. Maternal fecal microbiota transplantation in Cesarean-Born infants rapidly restores normal gut microbial development: a proofof-concept study. Cell 2020;183:324-34.

3 Lloyd-Price J, Mahurkar A, Rahnavard G, et al. Strains, functions and dynamics in the expanded human microbiome project. Nature 2017;550:61-6.

4 Barlow JT, Leite $\mathrm{G}$, Romano AE, et al. Quantitative sequencing clarifies the role of disruptor taxa, oral microbiota, and strict anaerobes in the human small-intestine microbiome. Microbiome 2021;9:214.

5 Seekatz AM, Schnizlein MK, Koenigsknecht MJ, et al. Spatial and temporal analysis of the stomach and small-intestinal microbiota in fasted healthy humans. mSphere 2019;4:e00126-19

6 Leite GGS, Weitsman S, Parodi G, et al. Mapping the segmental Microbiomes in the human small bowel in comparison with stool: a REIMAGINE study. Dig Dis Sci 2020;65:2595-604.

7 Zoetendal EG, Rajilic-Stojanovic M, de Vos WM. High-Throughput diversity and functionality analysis of the gastrointestinal tract microbiota. Gut 2008:57:1605-15.

8 Qin J, Li R, Raes J, et al. A human gut microbial gene Catalogue established by metagenomic sequencing. Nature 2010;464:59-65.

9 Rajilić-Stojanović M, de Vos WM. The first 1000 cultured species of the human gastrointestinal microbiota. FEMS Microbiol Rev 2014;38:996-1047.

10 Li J, Jia H, Cai X, et al. An integrated catalog of reference genes in the human gut microbiome. Nat Biotechnol 2014;32:834-41.

11 van Nood E, Vrieze A, Nieuwdorp M, et al. Duodenal infusion of donor feces for recurrent Clostridium difficile. N Engl J Med 2013;368:407-15.

12 Lynch SV, Pedersen 0. The human intestinal microbiome in health and disease. $N$ Engl J Med 2016;375:2369-79.

13 Fan Y, Pedersen 0. Gut microbiota in human metabolic health and disease. Nat Rev Microbiol 2021;19:55-71.

14 Hanssen NMJ, de Vos WM, Nieuwdorp M. Fecal microbiota transplantation in human metabolic diseases: from a murky past to a bright future? Cell Metab 2021;33:1098-110.

15 Wang R, Tang R, Li B, et al. Gut microbiome, liver immunology, and liver diseases. Cell Mol Immunol 2021;18:4-17.

16 O'Grady J, Murphy CL, Barry L, et al. Defining gastrointestinal transit time using video capsule endoscopy: a study of healthy subjects. Endosc Int Open 2020;8:E396-400.

17 Ding Z, Wang W, Zhang K, et al. Novel scheme for non-invasive gut bioinformation acquisition with a magnetically controlled sampling capsule endoscope. Gut 2021;70:2297-306. 
18 Ph van Trijp M, Wilms E, Ríos-Morales M, et al. Using naso- and oro-intestinal catheters in physiological research for intestinal delivery and sampling in vivo: practical and technical aspects to be considered. Am J Clin Nutr 2021;114:843-61.

19 Booijink CCGM, El-Aidy S, Rajilić-Stojanović M, et al. High temporal and interindividual variation detected in the human ileal microbiota. Environ Microbiol 2010;12:3213-27.

20 Zoetendal EG, Raes J, van den Bogert B, et al. The human small intestinal microbiota is driven by rapid uptake and conversion of simple carbohydrates. Isme J 2012;6:1415-26.

21 Lema I, Araújo JR, Rolhion N, et al. Jejunum: the understudied meeting place of dietary lipids and the microbiota. Biochimie 2020;178:124-36.

22 Wang M, Ahrné S, Jeppsson B, et al. Comparison of bacterial diversity along the human intestinal tract by direct cloning and sequencing of $16 \mathrm{~S}$ rRNA genes. FEMS Microbiol Ecol 2005;54:219-31.

23 van Baar ACG, Nieuwdorp M, Holleman F, et al. The duodenum harbors a broad Untapped therapeutic potential. Gastroenterology 2018;154:773-7.

24 Vrieze A, Van Nood E, Holleman F, et al. Transfer of intestinal microbiota from lean donors increases insulin sensitivity in individuals with metabolic syndrome. Gastroenterology 2012;143:913-6.

25 Kootte RS, Levin E, Salojärvi J, et al. Improvement of insulin sensitivity after lean donor feces in metabolic syndrome is driven by baseline intestinal microbiota composition. Cell Metab 2017;26:611-9.

26 de Groot P, Nikolic T, Pellegrini S, et al. Faecal microbiota transplantation halts progression of human new-onset type 1 diabetes in a randomised controlled trial. Gut 2021;70:92-105

27 Troost FJ, van Baarlen $\mathrm{P}$, Lindsey $\mathrm{P}$, et al. Identification of the transcriptional response of human intestinal mucosa to Lactobacillus plantarum WCFS1 in vivo. BMC Genomics 2008:9:374.

28 van Baarlen P, Troost FJ, van Hemert S, et al. Differential NF-kappaB pathways induction by Lactobacillus plantarum in the duodenum of healthy humans correlating with immune tolerance. Proc Natl Acad Sci U S A 2009;106:2371-6.

29 van Baarlen $\mathrm{P}$, Troost $\mathrm{F}$, van der Meer $\mathrm{C}$, et al. Human mucosal in vivo transcriptome responses to three lactobacilli indicate how probiotics may modulate human cellular pathways. Proc Natl Acad Sci U SA 2011;108 Suppl $1: 4562-9$

30 Shetty SA, Zuffa S, Bui TPN, et al. Reclassification of Eubacterium hallii as Anaerobutyricum hallii gen. nov., comb. nov., and description of Anaerobutyricum soehngenii sp. nov., a butyrate and propionate-producing bacterium from infant faeces. Int J Syst Evol Microbiol 2018;68:3741-6.

31 Koopen A, Witjes J, Wortelboer K, et al. Duodenal Anaerobutyricum soehngenii infusion stimulates GLP-1 production, ameliorates glycaemic control and beneficially shapes the duodenal transcriptome in metabolic syndrome subjects: a randomised double-blind placebo-controlled cross-over study. Gut 2021. doi:10.1136/ gutjnl-2020-323297. [Epub ahead of print: 25 Oct 2021].

32 Gilijamse PW, Hartstra AV, Levin E, et al. Treatment with Anaerobutyricum soehngenii: a pilot study of safety and dose-response effects on glucose metabolism in human subjects with metabolic syndrome. NPJ Biofilms Microbiomes 2020;6:16.

33 Swidsinski A, Loening-Baucke V, Verstraelen $\mathrm{H}$, et al. Biostructure of fecal microbiota in healthy subjects and patients with chronic idiopathic diarrhea. Gastroenterology 2008:135:568-79.

34 Cani PD. Human gut microbiome: hopes, threats and promises. Gut 2018;67:1716-25

35 Lloyd-Price J, Arze C, Ananthakrishnan AN, et al. Multi-Omics of the gut microbial ecosystem in inflammatory bowel diseases. Nature 2019;569:655-62.

36 Leonard MM, Valitutti F, Karathia $\mathrm{H}$, et al. Microbiome signatures of progression toward celiac disease onset in at-risk children in a longitudinal prospective cohort study. Proc Natl Acad Sci U S A 2021;118:e2020322118.

37 Mars RAT, Yang Y, Ward T, et al. Longitudinal multi-omics reveals Subset-Specific mechanisms underlying irritable bowel syndrome. Cell 2020;183:1137-40.

38 Tilg $H$, Adolph TE, Gerner RR, et al. The intestinal microbiota in colorectal cancer. Cancer Cell 2018:33:954-64.

39 Tilg H, Cani PD, Mayer EA. Gut microbiome and liver diseases. Gut 2016;65:2035-44

40 Trebicka J, Macnaughtan J, Schnabl B, et al. The microbiota in cirrhosis and its role in hepatic decompensation. J Hepatol 2021;75 Suppl 1:S67-81.

41 Adolph TE, Mayr L, Grabherr F, et al. Pancreas-Microbiota cross talk in health and disease. Annu Rev Nutr 2019;39:249-66.

42 Riquelme $E$, Zhang $Y$, Zhang L, et al. Tumor microbiome diversity and composition influence pancreatic cancer outcomes. Cell 2019;178:795-806.

43 Depommier C, Everard A, Druart C, et al. Supplementation with Akkermansia muciniphila in overweight and obese human volunteers: a proof-of-concept exploratory study. Nat Med 2019;25:1096-103.

44 Qin J, Li Y, Cai Z, et al. A metagenome-wide association study of gut microbiota in type 2 diabetes. Nature 2012;490:55-60.

45 Karlsson FH, Tremaroli V, Nookaew I, et al. Gut metagenome in European women with normal, impaired and diabetic glucose control. Nature 2013;498:99-103.

$46 \mathrm{Wu} \mathrm{H}$, Tremaroli V, Schmidt C, et al. The gut microbiota in prediabetes and diabetes: a population-based cross-sectional study. Cell Metab 2020;32:379-90.
47 Loomba R, Seguritan V, Li W, et al. Gut Microbiome-Based metagenomic signature for non-invasive detection of advanced fibrosis in human nonalcoholic fatty liver disease. Cell Metab 2019;30:607

48 Frost $F$, Kacprowski T, Rühlemann M, et al. Long-Term instability of the intestinal microbiome is associated with metabolic liver disease, low microbiota diversity, diabetes mellitus and impaired exocrine pancreatic function. Gut 2021;70:522-30.

49 Cani PD, Van Hul M. Do diet and microbes really 'PREDICT' cardiometabolic risks? Nat Rev Endocrinol 2021;17:259-60.

50 Cani PD, Moens de Hase E, Van Hul M. Gut microbiota and host metabolism: from proof of concept to therapeutic intervention. Microorganisms 2021;9:1302.

51 Cani PD, Van Hul M. Mediterranean diet, gut microbiota and health: when age and calories do not add up! Gut 2020;69:1167-8.

52 Cani PD, Jordan BF. Gut microbiota-mediated inflammation in obesity: a link with gastrointestinal cancer. Nat Rev Gastroenterol Hepatol 2018;15:671-82.

53 Louis P, Flint HJ. Formation of propionate and butyrate by the human colonic microbiota. Environ Microbiol 2017;19:29-41.

54 Chambers ES, Preston T, Frost G, et al. Role of gut Microbiota-Generated short-chain fatty acids in metabolic and cardiovascular health. Curr Nutr Rep 2018;7:198-206.

55 Frost G, Sleeth ML, Sahuri-Arisoylu M, et al. The short-chain fatty acid acetate reduces appetite via a central homeostatic mechanism. Nat Commun 2014;5:3611.

56 Canfora EE, Jocken JW, Blaak EE. Short-Chain fatty acids in control of body weight and insulin sensitivity. Nat Rev Endocrinol 2015;11:577-91.

57 Rastelli M, Cani PD, Knauf C. The gut microbiome influences host endocrine functions. Endocr Rev 2019:40:1271-84.

58 Daubioul CA, Taper HS, De Wispelaere LD, et al. Dietary oligofructose lessens hepatic steatosis, but does not prevent hypertriglyceridemia in obese Zucker rats. J Nutr 2000;130:1314-9.

59 Cani PD, Dewever C, Delzenne NM. Inulin-type fructans modulate gastrointestinal peptides involved in appetite regulation (glucagon-like peptide-1 and ghrelin) in rats. Br J Nutr 2004:92:521-6.

60 Cani PD, Neyrinck AM, Maton N, et al. Oligofructose promotes satiety in rats fed a high-fat diet: involvement of glucagon-like peptide-1. Obes Res 2005;13:1000-7.

61 Cani PD, Knauf C, Iglesias MA, et al. Improvement of glucose tolerance and hepatic insulin sensitivity by oligofructose requires a functional glucagon-like peptide 1 receptor. Diabetes 2006:55:1484-90.

62 Delzenne NM, Cani PD, Daubioul C, et al. Impact of inulin and oligofructose on gastrointestinal peptides. Br J Nutr 2005;93 Suppl 1:S157-61.

63 Cani PD, Hoste S, Guiot Y, et al. Dietary non-digestible carbohydrates promote L-cell differentiation in the proximal colon of rats. Br J Nutr 2007:98:32-7.

64 Everard A, Lazarevic V, Derrien M, et al. Responses of gut microbiota and glucose and lipid metabolism to prebiotics in genetic obese and diet-induced leptin-resistant mice. Diabetes 2011:60:2775-86.

65 Cani PD, Possemiers S, Van de Wiele T, et al. Changes in gut microbiota control inflammation in obese mice through a mechanism involving GLP-2-driven improvement of gut permeability. Gut 2009;58:1091-103.

66 Wang X, Gibson GR. Effects of the in vitro fermentation of oligofructose and inulin by bacteria growing in the human large intestine. J Appl Bacteriol 1993;75:373-80.

67 Aziz AA, Kenney LS, Goulet B, et al. Dietary starch type affects body weight and glycemic control in freely fed but not energy-restricted obese rats. J Nutr 2009:139:1881-9

68 Keenan MJ, Zhou J, McCutcheon KL, et al. Effects of resistant starch, a non-digestible fermentable fiber, on reducing body fat. Obesity 2006;14:1523-34.

69 Zhou J, Martin RJ, Tulley RT, et al. Dietary resistant starch upregulates total GLP-1 and PYY in a sustained day-long manner through fermentation in rodents. Am J Physiol Endocrinol Metab 2008;295:E1160-6.

70 Bui TPN, Ritari J, Boeren S, et al. Production of butyrate from lysine and the Amadori product fructoselysine by a human gut commensal. Nat Commun 2015;6:10062.

71 Bui TPN, Mannerås-Holm L, Puschmann R, et al. Conversion of dietary inositol into propionate and acetate by commensal Anaerostipes associates with host health. Nat Commun 2021;12:4798.

72 Rajilić-Stojanović M, Shanahan F, Guarner F, et al. Phylogenetic analysis of dysbiosis in ulcerative colitis during remission. Inflamm Bowel Dis 2013;19:481-8.

73 Brown AJ, Goldsworthy SM, Barnes AA, et al. The orphan G protein-coupled receptors GPR41 and GPR43 are activated by propionate and other short chain carboxylic acids. J Biol Chem 2003;278:11312-9.

74 Le Poul E, Loison C, Struyf $\mathrm{S}$, et al. Functional characterization of human receptors for short chain fatty acids and their role in polymorphonuclear cell activation. J Biol Chem 2003;278:25481-9.

75 Kimura I, Inoue D, Hirano K, et al. The SCFA receptor GPR43 and energy metabolism. Front Endocrinol 2014:5:85.

76 Nøhr MK, Pedersen MH, Gille A, et al. GPR41/FFAR3 and GPR43/FFAR2 as cosensors for short-chain fatty acids in enteroendocrine cells vs FFAR3 in enteric neurons and FFAR2 in enteric leukocytes. Endocrinology 2013;154:3552-64.

77 Brooks L, Viardot A, Tsakmaki A, et al. Fermentable carbohydrate stimulates FFAR2dependent colonic PYY cell expansion to increase satiety. Mol Metab 2017:6:48-60.

78 Psichas A, Sleeth ML, Murphy KG, et al. The short chain fatty acid propionate stimulates GLP-1 and PYY secretion via free fatty acid receptor 2 in rodents. Int J Obes 2015:39:424-9. 
79 Koh A, De Vadder F, Kovatcheva-Datchary P, et al. From dietary fiber to host physiology: short-chain fatty acids as key bacterial metabolites. Cell 2016;165:1332-45.

80 Litvak Y, Byndloss MX, Tsolis RM, et al. Dysbiotic Proteobacteria expansion: a microbial signature of epithelial dysfunction. Curr Opin Microbiol 2017;39:1-6.

81 Litvak Y, Mon KKZ, Nguyen H, et al. Commensal Enterobacteriaceae protect against Salmonella colonization through oxygen competition. Cell Host Microbe 2019:25:128-39.

82 Seksik P, Rigottier-Gois L, Gramet G, et al. Alterations of the dominant faecal bacterial groups in patients with Crohn's disease of the colon. Gut 2003;52:237-42

83 Morgan XC, Tickle TL, Sokol H, et al. Dysfunction of the intestinal microbiome in inflammatory bowel disease and treatment. Genome Biol 2012;13:R79.

84 Shelton CD, Byndloss MX. Gut epithelial metabolism as a key driver of intestinal dysbiosis associated with noncommunicable diseases. Infect Immun 2020;88:e00939-19.

85 Blaak EE, Canfora EE, Theis S, et al. Short chain fatty acids in human gut and metabolic health. Benef Microbes 2020;11:411-55

86 Le Roy T, Moens de Hase E, Van Hul M, et al. Dysosmobacter welbionis is a newly isolated human commensal bacterium preventing diet-induced obesity and metabolic disorders in mice. Gut 2021. doi:10.1136/gutjnl-2020-323778. [Epub ahead of print: 08 Jun 2021].

87 Shetty SA, Boeren S, Bui TPN, et al. Unravelling lactate-acetate and sugar conversion into butyrate by intestinal Anaerobutyricum and Anaerostipes species by comparative proteogenomics. Environ Microbiol 2020;22:4863-75.

88 Wang SP, Rubio LA, Duncan SH, et al. Pivotal roles for $\mathrm{pH}$, lactate, and LactateUtilizing bacteria in the stability of a human colonic microbial ecosystem. mSystems 2020:5:e00645-20.

89 Fernández-Veledo S, Vendrell J. Gut microbiota-derived succinate: friend or foe in human metabolic diseases? Rev Endocr Metab Disord 2019;20:439-47.

90 De Vadder F, Kovatcheva-Datchary P, Zitoun C, et al. Microbiota-Produced succinate improves glucose homeostasis via intestinal gluconeogenesis. Cell Metab 2016:24:151-7

91 Wang K, Liao M, Zhou N, et al. Parabacteroides distasonis alleviates obesity and metabolic dysfunctions via production of succinate and secondary bile acids. Cell Rep 2019;26:222-35

92 Tannahill GM, Curtis AM, Adamik J, et al. Succinate is an inflammatory signal that induces IL-1 $\beta$ through HIF-1 $\alpha$. Nature 2013;496:238-42.

93 Wan Y, Yuan J, Li J, et al. Overweight and underweight status are linked to specific gut microbiota and intestinal tricarboxylic acid cycle intermediates. Clin Nutr 2020;39:3189-98.

94 Bertani B, Ruiz N. Function and biogenesis of lipopolysaccharides. EcoSal Plus 2018;8:ESP-0001-2018

95 Walsh D, McCarthy J, O'Driscoll C, et al. Pattern recognition receptors--molecular orchestrators of inflammation in inflammatory bowel disease. Cytokine Growth Factor Rev 2013:24:91-104

96 Quesniaux VJ, Nicolle DM, Torres D, et al. Toll-like receptor 2 (TLR2)-dependentpositive and TLR2-independent-negative regulation of proinflammatory cytokines by mycobacterial lipomannans. J Immunol 2004;172:4425-34.

97 Poltorak A, He X, Smirnova I, et al. Defective LPS signaling in $\mathrm{C} 3 \mathrm{H} / \mathrm{HeJ}$ and C57BL/10ScCr mice: mutations in TLR4 gene. Science 1998;282:2085-8.

98 Belkaid Y, Harrison OJ. Homeostatic immunity and the microbiota. Immunity 2017:46:562-76.

99 Fitzgerald KA, Kagan JC. Toll-Like receptors and the control of immunity. Cell 2020:180:1044-66.

100 Cani PD, Amar J, Iglesias MA, et al. Metabolic endotoxemia initiates obesity and insulin resistance. Diabetes 2007:56:1761-72.

101 Régnier M, Van Hul M, Knauf C, et al. Gut microbiome, endocrine control of gut barrier function and metabolic diseases. J Endocrinol 2021:248:R67-82.

102 Tilg H, Burcelin R, Tremaroli V. Liver tissue microbiome in NAFLD: next step in understanding the gut-liver axis? Gut 2020:69:1373-4.

103 Anhê FF, Barra NG, Cavallari JF, et al. Metabolic endotoxemia is dictated by the type of lipopolysaccharide. Cell Rep 2021;36:109691.

104 Vijay-Kumar M, Aitken JD, Carvalho FA, et al. Metabolic syndrome and altered gut microbiota in mice lacking Toll-like receptor 5. Science 2010;328:228-31.

105 Vijay-Kumar M, Sanders CJ, Taylor RT, et al. Deletion of TLR5 results in spontaneous colitis in mice. J Clin Invest 2007;117:3909-21.

106 Takeda K, Akira S. Microbial recognition by Toll-like receptors. J Dermato/ Sci 2004;34:73-82.

107 Everard A, Geurts L, Caesar R, et al. Intestinal epithelial MyD88 is a sensor switching host metabolism towards obesity according to nutritional status. Nat Commun 2014; 5:5648.

108 Muccioli GG, Naslain D, Bäckhed F, et al. The endocannabinoid system links gut microbiota to adipogenesis. Mol Syst Biol 2010;6:392.

109 Cani PD, Plovier H, Van Hul M, et al. Endocannabinoids--at the crossroads between the gut microbiota and host metabolism. Nat Rev Endocrinol 2016;12:133-43.

110 Devane WA, Dysarz FA, Johnson MR, et al. Determination and characterization of a cannabinoid receptor in rat brain. Mol Pharmacol 1988;34:605-13.
111 Munro S, Thomas KL, Abu-Shaar M. Molecular characterization of a peripheral receptor for cannabinoids. Nature 1993:365:61-5.

112 Howlett AC, Barth F, Bonner TI, et al. International Union of pharmacology. XXVII. classification of cannabinoid receptors. Pharmacol Rev 2002:54:161-202.

113 Devane WA, Hanus L, Breuer A, et al. Isolation and structure of a brain constituent that binds to the cannabinoid receptor. Science 1992:258:1946-9.

114 Mechoulam R, Ben-Shabat S, Hanus L, et al. Identification of an endogenous 2-monoglyceride, present in canine gut, that binds to cannabinoid receptors. Biochem Pharmacol 1995:50:83-90.

115 Cristino L, Bisogno T, Di Marzo V. Cannabinoids and the expanded endocannabinoid system in neurological disorders. Nat Rev Neurol 2020;16:9-29.

116 Di Marzo V. New approaches and challenges to targeting the endocannabinoid system. Nat Rev Drug Discov 2018;17:623-39.

117 Syed SK, Bui HH, Beavers LS, et al. Regulation of GPR119 receptor activity with endocannabinoid-like lipids. Am J Physiol Endocrinol Metab 2012:303:E1469-78.

118 Depommier C, Vitale RM, Iannotti FA, et al. Beneficial effects of Akkermansia muciniphila are not associated with major changes in the circulating Endocannabinoidome but linked to higher Mono-Palmitoyl-Glycerol levels as new PPAR $\alpha$ agonists. Cells 2021;10:185.

119 Geurts L, Muccioli GG, Delzenne NM, et al. Chronic endocannabinoid system stimulation induces muscle macrophage and lipid accumulation in type 2 diabetic mice independently of metabolic endotoxaemia. PLoS One 2013;8:e55963.

120 Geurts L, Lazarevic V, Derrien M, et al. Altered gut microbiota and endocannabinoid system tone in obese and diabetic leptin-resistant mice: impact on apelin regulation in adipose tissue. Front Microbiol 2011;2:149.

121 Suriano F, Manca C, Flamand N, et al. Exploring the endocannabinoidome in genetically obese (ob/ob) and diabetic (db/db) mice: links with inflammation and gut microbiota. Biochim Biophys Acta Mol Cell Biol Lipids 2022;1867:159056.

122 Geurts L, Everard A, Van Hul M, et al. Adipose tissue NAPE-PLD controls fat mass development by altering the browning process and gut microbiota. Nat Commun 2015;6:6495.

123 Everard A, Plovier H, Rastelli M, et al. Intestinal epithelial Nacylphosphatidylethanolamine phospholipase D links dietary fat to metabolic adaptations in obesity and steatosis. Nat Commun 2019;10:457

124 Lefort C, Roumain M, Van Hul M, et al. Hepatic NAPE-PLD is a key regulator of liver lipid metabolism. Cells 2020;9:1247

125 Rastelli M, Van Hul M, Terrasi R, et al. Intestinal NAPE-PLD contributes to short-term regulation of food intake via gut-to-brain axis. Am J Physiol Endocrinol Metab 2020:319:E647-57

126 Manca C, Boubertakh B, Leblanc N, et al. Germ-Free mice exhibit profound gut microbiota-dependent alterations of intestinal endocannabinoidome signaling. J Lipid Res 2020;61:70-85.

127 Cohen LJ, Esterhazy D, Kim S-H, et al. Commensal bacteria make GPCR ligands that mimic human signalling molecules. Nature 2017;549:48-53.

128 Lefort C, Cani PD. The liver under the spotlight: bile acids and oxysterols as pivotal actors controlling metabolism. Cells 2021:10:400.

129 Chiang JYL, Ferrell JM. Bile acids as metabolic regulators and nutrient sensors. Annu Rev Nutr 2019:39:175-200.

130 Makishima M, Lu TT, Xie W, et al. Vitamin D receptor as an intestinal bile acid sensor. Science 2002:296:1313-6.

131 Ihunnah CA, Jiang M, Xie W. Nuclear receptor PXR, transcriptional circuits and metabolic relevance. Biochim Biophys Acta 2011;1812:956-63.

132 Wagner M, Halilbasic E, Marschall H-U, et al. Car and PXR agonists stimulate hepatic bile acid and bilirubin detoxification and elimination pathways in mice. Hepatology 2005:42:420-30.

133 Kuipers F, Bloks VW, Groen AK. Beyond intestinal soap--bile acids in metabolic control. Nat Rev Endocrinol 2014;10:488-98.

134 Ahmad TR, Haeusler RA. Bile acids in glucose metabolism and insulin signalling mechanisms and research needs. Nat Rev Endocrinol 2019:15:701-12.

135 Ridlon JM, Kang D-J, Hylemon PB. Bile salt biotransformations by human intestinal bacteria. J Lipid Res 2006:47:241-59.

136 Ridlon JM, Harris SC, Bhowmik S, et al. Consequences of bile salt biotransformations by intestinal bacteria. Gut Microbes 2016;7:22-39.

137 de Aguiar Vallim TQ, Tarling EJ, Edwards PA. Pleiotropic roles of bile acids in metabolism. Cell Metab 2013;17:657-69.

138 Jones BV, Begley M, Hill C, et al. Functional and comparative metagenomic analysis of bile salt hydrolase activity in the human gut microbiome. Proc Natl Acad Sci U SA 2008; 105:13580-5.

139 Sato Y, Atarashi K, Plichta DR, et al. Novel bile acid biosynthetic pathways are enriched in the microbiome of centenarians. Nature 2021:599:458-64.

140 Dong F, Perdew GH. The aryl hydrocarbon receptor as a mediator of host-microbiota interplay. Gut Microbes 2020;12:1859812.

141 Natividad JM, Agus A, Planchais J, et al. Impaired aryl hydrocarbon receptor ligand production by the gut microbiota is a key factor in metabolic syndrome. Cell Metab 2018:28:737-49.

142 Lin Y-H, Luck H, Khan S, et al. Aryl hydrocarbon receptor agonist indigo protects against obesity-related insulin resistance through modulation of intestinal and metabolic tissue immunity. Int J Obes 2019;43:2407-21. 
143 Scott SA, Fu J, Chang PV. Microbial tryptophan metabolites regulate gut barrier function via the aryl hydrocarbon receptor. Proc Natl Acad Sci U SA 2020;117:19376-87.

144 Grander C, Adolph TE, Wieser V, et al. Recovery of ethanol-induced Akkermansia muciniphila depletion ameliorates alcoholic liver disease. Gut 2018;67:891-901.

145 Wrzosek L, Ciocan D, Hugot C, et al. Microbiota tryptophan metabolism induces aryl hydrocarbon receptor activation and improves alcohol-induced liver injury. Gut 2021;70:1299-308.

146 Lamas B, Richard ML, Leducq V, et al. Card9 impacts colitis by altering gut microbiota metabolism of tryptophan into aryl hydrocarbon receptor ligands. Nat Med 2016;22:598-605.

147 Lamas B, Hernandez-Galan L, Galipeau HJ, et al. Aryl hydrocarbon receptor ligand production by the gut microbiota is decreased in celiac disease leading to intestinal inflammation. Sci Transl Med 2020;12:eaba0624.

148 Uberoi A, Bartow-McKenney C, Zheng Q, et al. Commensal microbiota regulates skin barrier function and repair via signaling through the aryl hydrocarbon receptor. Cell Host Microbe 2021;29:1235-48.

149 Erturk-Hasdemir D, Oh SF, Okan NA, et al. Symbionts exploit complex signaling to educate the immune system. Proc Natl Acad Sci U S A 2019. doi:10.1073/ pnas.1915978116. [Epub ahead of print: 06 Dec 2019].

150 Oh SF, Praveena T, Song H, et al. Host immunomodulatory lipids created by symbionts from dietary amino acids. Nature 2021;600:302-7.

151 Griffin ME, Espinosa J, Becker JL, et al. Enterococcus peptidoglycan remodeling promotes checkpoint inhibitor cancer immunotherapy. Science 2021:373:1040-6.

152 Konstantinov SR, Smidt H, de Vos WM, et al. S layer protein A of Lactobacillus acidophilus NCFM regulates immature dendritic cell and T cell functions. Proc Nat Acad Sci U S A 2008;105:19474-9.

153 Tytgat HLP, van Teijlingen NH, Sullan RMA, et al. Probiotic gut microbiota isolate interacts with dendritic cells via glycosylated heterotrimeric pili. PLoS One 2016;11:e0151824.

154 O'Connell Motherway M, Zomer A, Leahy SC, et al. Functional genome analysis of Bifidobacterium breve UCC2003 reveals type IVb tight adherence (TAD) pili as an essential and conserved host-colonization factor. Proc Natl Acad Sci U S A 2011;108:11217-22.

155 O'Connell Motherway M, Houston A, O'Callaghan G, et al. A bifidobacteria pilus-associated protein promotes colonic epithelial proliferation. Mol Microbiol 2019:111:287-301

156 Breton J, Tennoune N, Lucas N, et al. Gut Commensal E. coli Proteins Activate Host Satiety Pathways following Nutrient-Induced Bacterial Growth. Cell Metab 2016;23:324-34.

157 Legrand R, Lucas N, Dominique M, et al. Commensal Hafnia alvei strain reduces food intake and fat mass in obese mice-a new potential probiotic for appetite and body weight management. Int J Obes 2020;44:1041-51.

158 Depommier C, Everard A, Druart C, et al. Serum metabolite profiling yields insights into health promoting effect of $A$. muciniphila in human volunteers with a metabolic syndrome. Gut Microbes 2021:13:1994270.

159 Yoon HS, Cho CH, Yun MS, et al. Akkermansia muciniphila secretes a glucagon-like peptide-1-inducing protein that improves glucose homeostasis and ameliorates metabolic disease in mice. Nat Microbiol 2021;6:563-73.

160 Cani PD, Knauf C. A newly identified protein from Akkermansia muciniphila stimulates GLP-1 secretion. Cell Metab 2021;33:1073-5.

161 Meng X, Zhang J, Wu H, et al. Akkermansia muciniphila Aspartic Protease Amuc 1434* Inhibits Human Colorectal Cancer LS174T Cell Viability via TRAILMediated Apoptosis Pathway. Int J Mol Sci 2020;21:3385.

162 Depommier C, Van Hul M, Everard A, et al. Pasteurized Akkermansia muciniphila increases whole-body energy expenditure and fecal energy excretion in diet-induced obese mice. Gut Microbes 2020:11:1231-45.

163 Plovier H, Everard A, Druart C, et al. A purified membrane protein from Akkermansia muciniphila or the pasteurized bacterium improves metabolism in obese and diabetic mice. Nat Med 2017;23:107-13.

164 Ottman N, Reunanen J, Meijerink M, et al. Pili-like proteins of Akkermansia muciniphila modulate host immune responses and gut barrier function. PLoS One 2017; 12:e0173004

165 Ottman N, Davids M, Suarez-Diez M, et al. Genome-Scale Model and Omics Analysis of Metabolic Capacities of Akkermansia muciniphila Reveal a Preferential MucinDegrading Lifestyle. App/ Environ Microbiol 2017;83:e01014-7.

166 Knauf C, Abot A, Wemelle E, et al. Targeting the Enteric Nervous System to Treat Metabolic Disorders? "Enterosynes" as Therapeutic Gut Factors. Neuroendocrinology 2020;110:139-46.
167 Fournel A, Drougard A, Duparc T, et al. Apelin targets gut contraction to control glucose metabolism via the brain. Gut 2017;66:258-69.

168 Knauf C, Cani PD, Perrin C, et al. Brain glucagon-like peptide-1 increases insulin secretion and muscle insulin resistance to favor hepatic glycogen storage. J Clin Invest 2005; 115:3554-63.

169 Abot A, Lucas A, Bautzova T, et al. Galanin enhances systemic glucose metabolism through enteric nitric oxide Synthase-expressed neurons. Mol Metab 2018;10:100-8

170 Abot A, Wemelle $E$, Laurens $C$, et al. Identification of new enterosynes using prebiotics: roles of bioactive lipids and mu-opioid receptor signalling in humans and mice. Gut 2021;70:1078-87.

171 Abot A, Cani PD, Knauf C. Impact of intestinal peptides on the enteric nervous system: novel approaches to control glucose metabolism and food intake. Front Endocrinol 2018;9:328.

172 Pujo J, Petitfils C, Le Faouder P, et al. Bacteria-Derived long chain fatty acid exhibits anti-inflammatory properties in colitis. Gut 2021;70:1088-97.

173 Sakellariou S, Fragkou P, Levidou G, et al. Clinical significance of AGE-RAGE axis in colorectal cancer: associations with glyoxalase-I, adiponectin receptor expression and prognosis. BMC Cancer 2016:16:174.

174 Peppa M, Mavroeidi I. Experimental animal studies support the role of dietary advanced glycation end products in health and disease. Nutrients 2021;13:3467. doi:10.3390/nu13103467

175 Qu W, Yuan X, Zhao J, et al. Dietary advanced glycation end products modify gut microbial composition and partially increase colon permeability in rats. Mol Nutr Food Res 2017;61:mnfr.201700118:1700118

176 Wiame E, Delpierre G, Collard F, et al. Identification of a pathway for the utilization of the Amadori product fructoselysine in Escherichia coli. J Biol Chem 2002:277:42523-9.

177 TPN B, Troise AD, Nijsse B. Intestinimonas-like bacteria are important butyrate producers that utilize $\mathrm{N} \varepsilon$-fructosyllysine and lysine in formula-fed infants and adults. Journal of Functional Foods 2020;70:103974.

178 Bui TPN, Troise AD, Fogliano V, et al. Anaerobic degradation of $\mathrm{N}-\varepsilon$ Carboxymethyllysine, a major glycation end-product, by human intestinal bacteria. J Agric Food Chem 2019;67:6594-602

179 Zeisel SH, Mar M-H, Howe JC, et al. Concentrations of choline-containing compounds and betaine in common foods. J Nutr 2003;133:1302-7.

180 Demarquoy J, Georges B, Rigault C, et al. Radioisotopic determination of $\mathrm{L}$-carnitine content in foods commonly eaten in Western countries. Food Chem 2004:86:137-42.

181 Brown JM, Hazen SL. Microbial modulation of cardiovascular disease. Nat Rev Microbiol 2018;16:171-81.

182 Koay YC, Chen Y-C, Wali JA, et al. Plasma levels of trimethylamine-N-oxide can be increased with 'healthy' and 'unhealthy' diets and do not correlate with the extent of atherosclerosis but with plaque instability. Cardiovasc Res 2021;117:435-49.

183 Velasquez MT, Ramezani A, Manal A, et al. Trimethylamine N-oxide: the good, the bad and the unknown. Toxins 2016:8:326.

184 Picking JW, Behrman EJ, Zhang L, et al. MtpB, a member of the MttB superfamily from the human intestinal acetogen Eubacterium limosum, catalyzes proline betaine demethylation. J Biol Chem 2019;294:13697-707.

185 Kountz DJ, Behrman EJ, Zhang L, et al. MtcB, a member of the MttB superfamily from the human gut acetogen Eubacterium limosum, is a cobalamin-dependent carnitine demethylase. J Biol Chem 2020;295:11971-81.

186 Feng Y, Bui TPN, Stams AJM, et al. Comparative genomics and proteomics of Eubacterium maltosivorans: functional identification of trimethylamine methyltransferases and bacterial microcompartments in a human intestinal bacterium with a versatile lifestyle. Environ Microbiol 2022. doi:10.1111/14622920.15886. [Epub ahead of print: 02 Jan 2022].

187 Molinaro A, Bel Lassen P, Henricsson M, et al. Imidazole propionate is increased in diabetes and associated with dietary patterns and altered microbial ecology. Nat Commun 2020;11:5881.

188 Koh A, Molinaro A, Ståhlman M, et al. Microbially produced imidazole propionate impairs insulin signaling through mTORC1. Cell 2018;175:947-61.

189 Van Hul M, Le Roy T, Prifti E, et al. From correlation to causality: the case of Subdoligranulum. Gut Microbes 2020;12:1-13.

190 Sender R, Fuchs S, Milo R. Are we really Vastly Outnumbered? revisiting the ratio of bacterial to host cells in humans. Cell 2016:164:337-40.

191 Neugent ML, Hulyalkar NV, Nguyen VH, et al. Advances in understanding the human urinary microbiome and its potential role in urinary tract infection. $\mathrm{mBio}$ 2020;11:e00218-20. 